\title{
Nuevo tipo de apoyos y articulakiones
}

\author{
FRITZ LEONHARDT y WOLFHART ANDRÄ, ingenieros
}

\section{sing apsis}

Las tendencias actuales son funciones que dependen directamente de la presencia creciente y mejorada de los materiales de construcción que se ofrecen al comercio. En el campo de los materiales cabe una marcada subdivisión en naturales y preparados o sintéticos; estos últimos constituyen la preocupación de los autores para su apro. vechamiento $\mathrm{y}$ adecuada aplicación. De entre ellos, las resinas sintéticas o caucho artificial, dentro de las distintas especies de la extensa familia han gozado de un lugar preferente en este estudio de nuevos tipos de apoyos que presentan los notables ingenieros alemanes Wolfhart Andrä y Fritz Leonhardt.

En los ensayos de laboratorio y a escala natural, las variedades comerciales de estas resinas, conocidas con los nombres de «neopreno» y \&Teflon», han sido elegidas por presentar, por lo menos actualmente, caracteristicas marcadamente apropiadas a la finalidad perseguida en este estudio, del que se confia ulterior desarrollo y mejor acogida, por las importantes aplicaciones que de él se derivan en el campo de la ingeniería y construcción.

Los autores estudian con detenimiento y sobrado rigor para las aplicaciones prácticas las deformaciones que de estos materiales se espera al someterlos a fuerzas de gran concentración.

En los apoyos juega particular interés la distribución de la carga siempre concentrada en superficies relativamente pequeñas, lo que exige elevadas cargas unitarias y, con ello, la utilización de materiales extremadamente nobles para resistirlas con la resistencia que las deformaciones instantáneas requieren para recobrar rápidamente la posición de estabilidad perdida momentáneamente. La fatiga en el ciclo de deformaciones relaja los materiales, y ha de tenerse presente al considerar las características que los materiales empleados en los apoyos han de tener.

Llevando las cosas a límites extremos se aprecia con mayor facilidad la importancia de un fenómeno y, si consideramos un apoyo imaginado de reducida superficie de sustentación, comprenderemos que, en el límite, los esfuerzos pueden presentar (remotamente) caracteres puntuales o lineales, o, más gráficamente, de aguja o fllo incisivo, de graves consecuencias.

La presencia de estos materiales y su racional aplicación reducen considerablemente las superficies de sustentacíon hasta hoy necesarias con los materiales ordinarios.

Otro fenómeno a considerar es la rigidez, en muchos casos necesaria, que los autores también han estudiado analí ticamente en este trabajo.

Se han tratado con singular acierto las comparaciones entre los apoyos $y$ articulaciones ordinarias y los que se obtienen con los nuevos materiales.

Los autores han reservado amplio espacio a las distintas clases de apoyos, de los que se acompaña una valiosa información gráfica, debidamente acotada para las posibles aplicaciones.

Constituye una característica importante la movilidad que en determinados casos ha de exigirse de los apoyos, ya que éstos han de permitir ciertos movimientos por distintas causas, como, por ejemplo, diferencias de temperatura. Esta particularidad ha sido motivo de estudio y consideración en este trabajo.

El apoyo tiene sus dimensiones óptimas, cuya determinación se ha tratado con suficiente detalle para las aplicaeiones ordinarias que la práctica exige.

También han dejado prever los autores las posibilidades futuras que se ofrecen a este nuevo tipo de apoyo.

Para terminar, cierra el trabajo una serie de objeciones de carácter técnico-térico de todos los tipos de apoyo que han sido tratados en el texto y dan cuenta de su agradecimiento a las distintas personalidades e instituciones ale. manas por la colaboración de ellas recibida. 


\section{Sîtuaceióm}

La exposición del jardín celebrada en Stuttgart, 1961, se aprovechó para modificar convenientemente el núcleo de la ciudad. La rosaleda del palacio nuevo se continuaba con hermosos parques y avenidas, que se extendían hacia el Neckar formando una mancha verde que, con el cruce de ferrocarriles y calles, había perdido calidad estética en el transcurso de los últimos decenios. Los tapices verdes salpicados aquí y allá con grupos de árboles centenarios de magnífico porte han sido atravesados por una calle transversal; otras dos, también transversales, han sido ensanchadas y se han establecido pasarelas para facilitar el acceso y la circulación a los numerosos peatones que allí acuden en busca de reposo y distracción. La primera y principal de estas pasarelas, objeto de este artículo, es la que cruza la calle de Schiller, estableciendo comunicación directa entre el Landtag (palacio provincial) y dos teatros por un lado y la estación principal por otro (fig. 1). Esta pasarela, desde la época de la exposición, ha ido adquiriendo cada vez más importancia. A un lado y otro de la misma se han construido estanques, piscinas, sendas de jardín, bibliotecas, pequeños cafés, etc., deformando un núcleo de descanso y recreo en el mismo corazón de la ciudad. Esta ubicación especial no debe perderse de vista para darse cuenta de que la construcción ha de acomodarse a circunstancias poco corrientes.

\section{El pBrognectit}

El municipio de Stuttgart encargó a los autores la redacción de proyectos de comparación para resolver el problema. Dada la gran circulación de personas que era de prever se hizo necesaria la supresión de escaleras, sustituyéndolas por rampas. La rasante debía ser lo menos alta posible para evitar las subidas inútiles. En el lado de la estación había que pensar que unos peatones se dirigirían a la estación y otros a! parque, de modo que se necesitaba una bifurcación. El arquitecto encargado de los jardines deseaba que esta bifurcación fuese relativamente grande y se calculaba, aproximadamente, para una banda larga y volumen constante, midiendo las superficies laterales de henchimiento (figura 2a) con la fórmula:

$$
\Delta h=\frac{2 F_{1}}{b}
$$

En la hipótesis de que la dilatación transversal del colchón de neopreno sometido a compresión en sus superficies de arriba y abajo queda por completo coartada (impedida) por la adherencia y el rozamiento, puede determinarse con relativa sencillez la contracción, $\Delta h$, y la rigidez de compresión, $R_{D}$

La rigidez a la compresión es la fuerza necesaria para producir la contracción $\Delta h=1$.

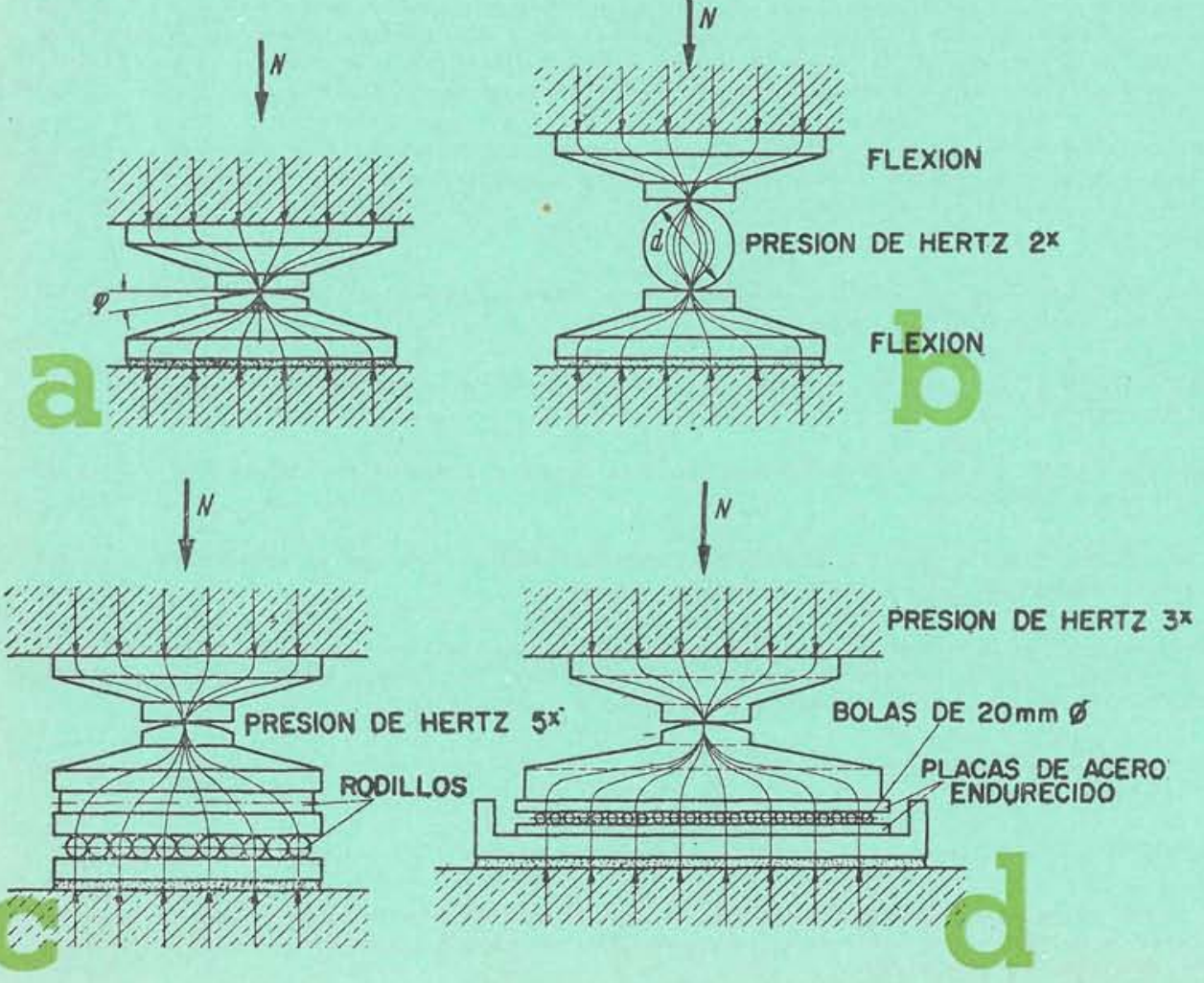
Fig. 1.-Apoyos corrientes de neopreno.
a) Con giro puntual o punto, p. ef., para $16 \mathrm{Mp} / \mathrm{cm}^{2}$, la pre- sión de Hertz para $\mathbf{N}=384 \mathrm{Mp} ; \boldsymbol{r}$ necess rio $=150 \mathrm{~cm}$; excentri- cidad para $\varphi=0,02 \ldots$ $\mathrm{e}=\mathrm{r} \varphi=3 \mathrm{~cm}$.
b) Apoyo de corrimiento lineal. Presion de Hertz, aprox. $16 \mathrm{Mp} /$ $\mathrm{cm}^{2}$ tipo corroweld Esslingen).
c) Giro puntual y corri- miento en cualquier cruzadas de rodillos.
d) Giro puntual, corri- miento en todas di- recciones, con bolas sobre marco de ro- tención.


Fig. 2.-Apoyos de

a) Apoyo sencillo presión admisible: hasta $\mathrm{p}=30 \mathrm{kp} /$ prop proporcional a la $\mathrm{F}_{1}$. Corrimient horizontal admisible, máx $0,9 \mathrm{~h}$.

Apoyos de capas de neopreno.

b) Apoyos de capas de neopreno con chapas de acero sion sion admisible, hasta unos 100 sión proporcional a las superficies rayadas $\Sigma \mathrm{F}_{2}<\mathrm{F}_{1}$. Corrimiento horizontal admisible como en la figura a), cuando $\Sigma h_{1}=h$.

c) y d) Apoyos en los que se ve el corrimiento horizontal.
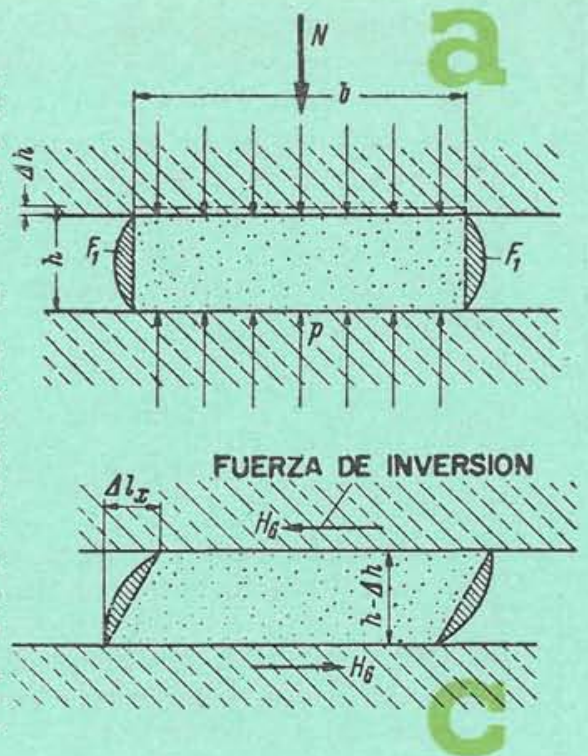
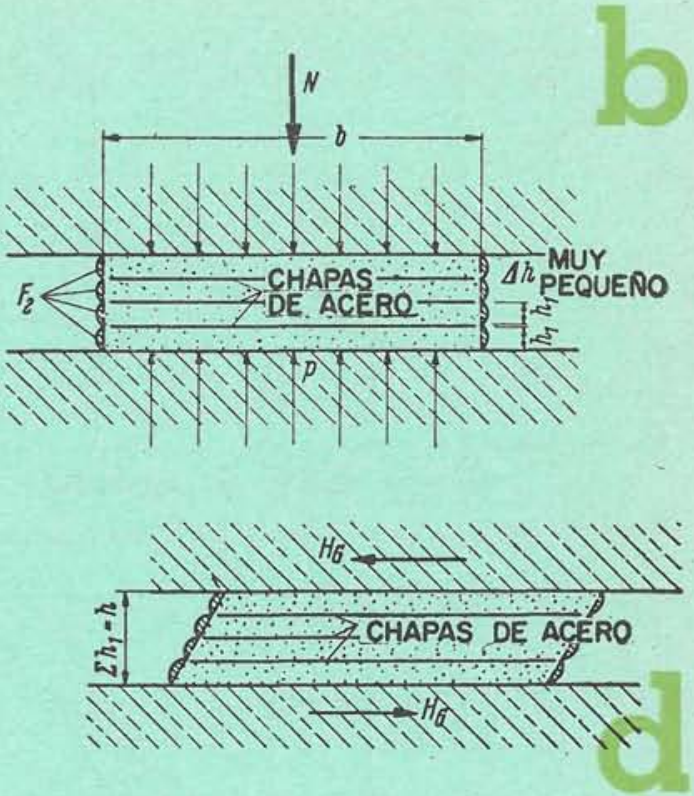

Se halla-sin entrar en detalles sobre ello-por la fórmula:

$$
R_{\mathrm{D}}=\frac{F_{\mathrm{G}} \cdot E_{0}}{h} \cdot \frac{\left(1+0,5 \cdot \mu \cdot n^{2}\right)}{1-\mu^{2}}[\mathrm{kp} / \mathrm{cm}]\left({ }^{\circ}\right)
$$

en que:

$b=$ anchura de la placa de neopreno (pequeña comparada con su longitud),

$h=$ espesor de la placa de neopreno,

$F_{\mathrm{G}}=$ superficie comprimida,

$E_{0}=$ módulo de elasticidad con dilatación transversal libre,

$\mu=$ coeficiente de Poisson,

$n=$ factor de forma $b / h$.

En la fórmula [2] se han tenido solamente en cuenta las deformaciones transversales en dirección de la anchura $b$; por el contrario, se han despreciado las longitudinales, lo cual puede admitirse cuando la longitud es grande comparada con la anchura. Se ha supuesto, además, que las deformaciones son pequeñas y que el abultamiento lateral tiene forma de parábola.

Sustituyendo en [2], en vez de

$$
E_{0} \cdot \frac{\left(1+0,5 \mu n^{2}\right)}{1-\mu^{2}}=E_{i, \mathrm{D}}\left[\mathrm{kp} / \mathrm{cm}^{2}\right]
$$

$\left({ }^{\circ}\right) \mathrm{kp}=\mathrm{kilopond}=\mathrm{kg} ; \mathrm{Mp}=$ Millionpond =tonelada. es decir: sustituyendo un módulo ideal de elasticidad que involucra, además del corriente, el factor de forma $n$ y el coeficiente $\mu$ de dilatación transversal, se obtiene para la rigidez de compresión, la conocida relación:

$$
R_{\mathrm{D}}=\frac{F_{\mathrm{G}} \cdot E_{i, \mathrm{D}}}{h}[\mathrm{kp} / \mathrm{cm}]
$$

Para el neopreno blando puede aceptarse para el coeficiente de dilatación transversal el valor $\mu=0,5$, ya que el material es casi incompresible.

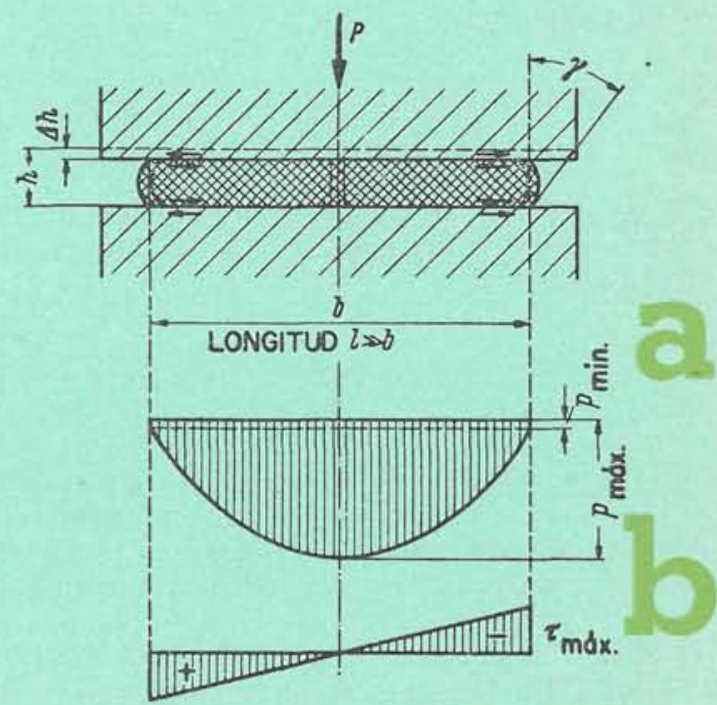

Fig. 3.-Distribución de cargas de compresión y tangenciales sobre una placa larga de neopreno, las earas superior e inferior; solicitación centrada. 


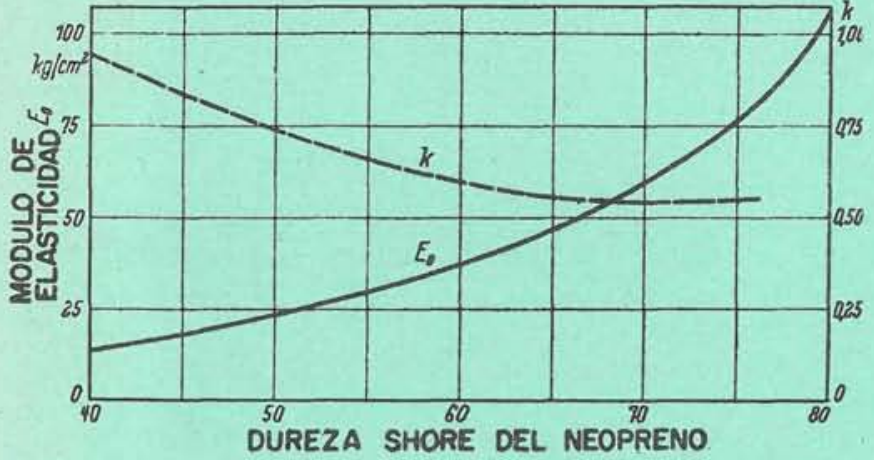

Fig. 4.-Dependencia de $E_{0} y$ de $k$ con la dureza Shore (según Gent).

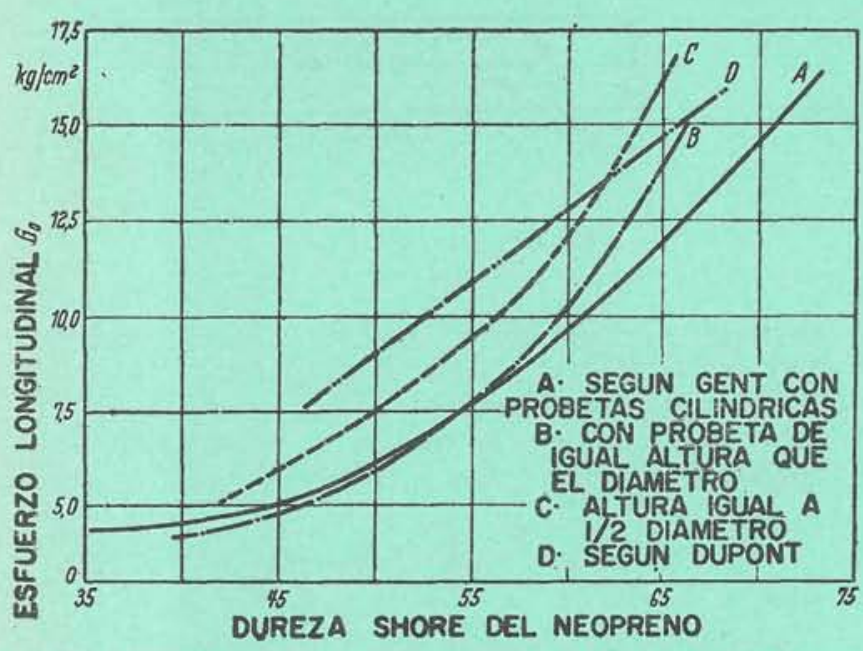

Fig. 5.-Dependencia entre el módulo tangencial y la dureza Shore segú los ensayos.

Con esto, sale de [3] el módulo ideal de elasticidad a compresión:

$$
E_{i, \mathrm{D}}=E_{0} \frac{\left(1+0,25 n^{2}\right)}{0,75}=E_{0} \cdot \frac{4}{3}\left(1+0,25 n^{2}\right)
$$

A una relación análoga llega A. N. Gent en (1). El módulo ideal de elasticidad para la compresión es (según Gent):

$E_{i, \mathrm{D}}=E_{0} \cdot \frac{4}{3} \cdot\left(1+k \cdot 0,25 n^{2}\right)\left[\mathrm{kp} / \mathrm{cm}^{2}\right]$

en la que, con el factor $k$ se tiene en cuenta la variación del coeficiente de dilatación transversal en los neoprenos más duros. En la figura 4 se ha representado gráficamente la dependencia entre el coeficiente $\mathrm{k}$ y la dureza Shore. Para neoprenos muy blandos (dureza Shore $<40$ ) $k$ es $\sim 1,0$, con lo que el valor [3b] dado por Gent coincide con el [3a]. En la figura 4 se ven también los valores de los módulos de elasticidad hallados por Gent, en función de la dureza Shore. Con la figura a la vista es fácil determinar la rigidez de compresión de una placa de neopreno, dentro de las hipótesis admitidas.

Así, por ejemplo, en una banda larga de neopreno, con anchura $b=30 \mathrm{~cm}$; espesor $h=0,5 \mathrm{~cm}$, y dureza Shore $=65$, la figura 4 nos da $E_{0}=47 \mathrm{kp} / \mathrm{cm}^{2}$; $k=0,56$. Con $n=b / h=30 / 0,5=60$ se deduce de [3b] para el módulo ideal de elasticidad a compresión, el valor:

$$
\begin{gathered}
E_{i, \mathrm{D}}=47 \cdot \frac{4}{3} \cdot(1+0,56 \cdot 0,25 \cdot 3.600)=47 \cdot 670= \\
=31.500 \mathrm{kp} / \mathrm{cm}^{2}
\end{gathered}
$$

El hecho de coartar la dilatación transversal corresponde en este caso a un aumento del módulo $E_{0}$ de elasticidad, que es 670 veces su valor, o, lo que es equivalente: la contracción $\Delta h$ disminuye hasta $1 / 670=1,5$ por 1.000 de la contracción que se produce con dilatación libre.

Tiene también interés en este caso la distribución de presiones en la dirección transversal de la superficie de apoyo. Como en el interior de la placa de neopreno es máxima la coacción de la dilatación transversal, tanto la rigidez como las cargas de compresión serán máximas en la zona central del interior. En cambio, hacia los bordes libres el neopreno puede expansionarse con más libertad y la dilatación transversal será mayor. Por lo tanto, la rigidez y las cargas de compresión van disminuyendo según vamos hacia los bordes.

Bajo las hipótesis admitidas al principio, la distribución de las cargas de compresión sigue, aproximadamente, la ley parabólica (fig. 3a).

En la mitad de la placa, con $p_{m}=P / F_{\mathrm{G}}$ :

$$
\text { máx } p \sim\left(\frac{4+1,5 n^{2}}{4+n^{2}}\right) \cdot p_{m}\left[\mathrm{kp} / \mathrm{cm}^{2}\right]
$$

y en los bordes:

$$
\text { mín } p \sim\left(\frac{4}{4+n^{2}}\right) p_{m}\left[\mathrm{kp} / \mathrm{cm}^{2}\right]
$$

La distribución de las correspondientes cargas tangenciales es lineal. Los valores máximos corresponden a los bordes de la placa, ya que aquí las deformaciones tangenciales son máximas debido a los abultamientos (fig. 3b).

De la constancia de volumen y con abultamientos parabólicos, se deduce para el ángulo máximo de deslizamiento el valor:

$$
\operatorname{tag} \gamma \sim\left(\frac{9 n}{4+n^{2}}\right) \frac{p_{m}}{E_{0}}
$$


y con esto la máxima carga tangencial:

máx $\tau=y \cdot G_{0}=\left(\frac{3 n}{4+n^{2}}\right) p_{m}\left[\mathrm{kp} / \mathrm{cm}^{2}\right]$

ya que con $\mu \cong 0,5$ el módulo tangencial es $G_{0} \cong$ $\cong \frac{1}{3} E_{0}$. Las expresiones [4a] a [4c] para valores grandes de $n$ coinciden con las expresiones dadas por Topaloff en la referencia bibliográfica (17).

En la práctica no es posible conseguir totalmente una coacción completa de la dilatación transversal en las caras superior e inferior de la placa. Tampoco puede garantizarse, de un modo absoluto, la constancia de volumen. Mediante añadidos que se emplean en la fabricación del neopreno, se han conseguido valores de $\mu<0,5$. Además, la mayor parte de las placas de apoyo son cuadradas o rectangulares poco alargadas, de modo que se producen deformaciones tangenciales en los dos sentidos. Con esto, el módulo ideal de elasticidad $E$ es menor que el dado por [3b]. Como consecuencia, los valores máx. $p$ y máx. $\tau$ son menores que los dados por [4a] y [4c]. Más adelante insistiremos sobre esta cuestión.

Las ecuaciones [2] y [3] muestran, sin embargo, que la contracción de compresión, $\Delta h$, es esencialmente menor cuando la dilatación transversal del apoyo disminuye al elegir un factor de forma, $n=b / h$, de valor grande.

Por otra parte, la movilidad horizontal, $\Delta l_{x}$, del apoyo-debida a la buena deformabilidad tangencial del neopreno hasta un cierto ángulo de deslizamiento tag $\gamma=\Delta l / h$ (fig. 2c)-depende de. $h$ y es máxima, próximamente para el valor $\Delta l_{x}=2,5 h$; como ángulo admisible de deslizamiento se adopta $\operatorname{tag} \gamma=\Delta l / h=0,9$.

Los mejores dispositivos de apoyo con pequeños $\Delta h$ y grande $\Delta l_{x}$ son los formados con varias capas de neopreno (de gran $b / h$ ) intercaladas con chapas de acero para dificultar la dilatación transversal: las chapas pueden colocarse simplemente o con vulcanización (fig. 2b) (2), (3), (13) y (15). En estos apoyos de varias capas pueden admitirse valores esencialmente mayores de la presión que en los de una sola capa de neopreno, aunque sea grande su espesor.

En las chapas se producen grandes cargas de tracción con sus correspondientes dilataciones, y esto hace posible una cierta dilatación de los neoprenos en sentido transversal. Para un apoyo de esta clase de $30 \times 40 \mathrm{~cm}$ de planta, con $n=b / h_{1}=60$, dureza Shore $=65$, el módulo ideal de elasticidad, según las referencias (8) y (15), es solamente de $E_{t \mathrm{D}}=$ $=11.250 \mathrm{kp} / \mathrm{cm}^{2}$.
Para una banda alargada de neopreno, con la misma relación $n=b / h_{1}=60$ se halló antes, suponiendo coacción completa en las dos caras superior e inferior, el valor teórico $E_{t, \mathrm{D}}=31.500 \mathrm{kp} / \mathrm{cm}^{2}$.

Este valor, para planta cuadrada-y debido a la deformación tangencial en dirección longitudinal-, disminuye próximamente hasta su valor mitad. $\mathrm{Si}$, además, se tiene en cuenta la menor coacción de los neoprenos, a causa de la dilatación de las chapas, el módulo ideai de compresión dado en las referencias (8) y (15) coincide, aproximadamente, con el valor teórico calculado.

Una coincidencia más aceptable se obtiene comparando con las mediciones efectuadas en el laboratorio de ensayos EMPA $\left({ }^{*}\right)$ de Zürich. Los neoprenos tenían $h_{1}=12 \mathrm{~mm}$ de espesor; $b=20$ a $30 \mathrm{~cm}$ de anchura $(n=16,7$ a 25$)$ y $l=30$ a $40 \mathrm{~cm}$ de longitud. Los valores calculados discrepan de los medidos en un 10 por 100 como término medio, siempre que se tenga en cuenta la siguiente relación de lados:

$$
E_{i, \mathrm{D}}{ }^{*}=E_{i, \mathrm{D}}\left(\frac{l}{l+b}\right)
$$

En la exposición que venimos haciendo, conviene destacar que el módulo de elasticidad $E_{0}$ y con él, el ideal $E_{1, \mathrm{D}}$, no solamente dependen esencialmente de la dureza Shore, sino también de la velocidad de la deformación y de la temperatura, por lo que los valores calculados y los medidos no pueden compararse sin tomar las debidas precauciones.

El corrimiento (traslación) horizontal admisible en los apoyos de varias capas de neopreno se fija también en $\Delta l_{x}=0,9 h$, es decir, lo mismo que en los apoyos de una capa.

La resistencia contra los corrimientos horizontales se determina con la rigidez tangencial, $\mathrm{R}_{\mathrm{S}}$, dada por:

$$
R_{\mathrm{S}}=\frac{F_{\mathrm{G}} \cdot G_{0}}{h}\left[\mathrm{kp} / \mathrm{cm}^{2}\right]
$$

La rigidez tangencial es la fuerza horizontal necesaria para que se produzca un corrimiento horizontal $\Delta l=1$ entre las caras superior e inferior de la placa de neopreno.

Para valores dados de $\Delta l$ y $h$, la fuerza horizontal vale:

$$
H_{\mathrm{G}}=R_{\mathrm{S}} \cdot \Delta l=F_{\mathrm{G}} \cdot G_{0} \cdot \frac{\Delta l}{h}[\mathrm{kp}]
$$

$\left({ }^{*}\right)$ EMPA $=$ Laboratorio Federal de Ensayo de Materiales. 
Agotando al máximo el valor del corrimiento horizontal admisible se nota la influencia perturbadora de la rigidez transversal.

Con $\Delta l=0,9 h$, el ángulo de deslizamiento es:

$$
\operatorname{tag} \gamma=\Delta l / h=0,9
$$

y la carga tangencial es:

$$
\tau=G_{0} \cdot \operatorname{tag} \gamma=0,9 \cdot G_{0}
$$

El módulo tangencial, $G_{0}$, se da en la figura 5 en función de la dureza Shore para deformaciones lentas. Los valores oscilan según las condiciones del ensayo. Como se ve en las líneas $B$ y $C$ el factor de forma desempeña un cierto papel. Con $65^{\circ}$ de dureza Shore, los valores medidos están comprendidos entre 12 y $16 \mathrm{kp} / \mathrm{cm}^{2}$. Si se calcula con $G_{0}=14 \mathrm{kp} / \mathrm{cm}^{2}$ como valor medio, para el corrimiento horizontal admisible se tiene, según [8], la carga tangencial, $\tau=0,9 \cdot 14=12,6 \mathrm{kp} / \mathrm{cm}^{2}$, y de aquí, la fuerza horizontal, $H_{\mathrm{G}}=F_{\mathrm{G}} \cdot \tau$, que es independiente de la presión, $p$.

Por ejemplo, en un apoyo con $N=100 \mathrm{Mp}$ de presión total de apoyo, siendo la carga práctica admisible $p=100 \mathrm{kp} / \mathrm{cm}^{2}$, el área de apoyo valdrá $F_{G}=100.000: 100=1.000 \mathrm{~cm}^{2}$ y, por lo tanto, $H_{\mathrm{G}}=1.000 \cdot 12,6 \mathrm{Mp}=12,6 \mathrm{Mp}$, o sea, en números redondos, 12,5 por 100 de la presión de apoyo en este caso, puesto que, en general, el valor es independiente de ella. Con valores pequeños de $N$ puede ocurrir un deslizamiento entre el neopreno y la construcción.

Por esto, debe siempre cuidarse que las superficies de neopreno se coloquen bien limpias y secas para que se adhieran perfectamente a las de la construcción. Según las normas del BVM (8), la fuerza $H_{G}$ para apoyos de una sola capa de neopreno no debe ser mayor que $0,30 N_{m i n}$ y para apoyos de varias capas no mayor que $0,15 N_{m i n}$; con esto se consigue una cierta seguridad contra este deslizamiento. Si se compara esta fuerza horizontal, $H_{G}$, con la $H$, que corresponde al rozamiento por rodadura (éste depende de $N$ y vale aproximadamente 1 por 100 de $N$ ), se ve que para neoprenos con gran ángulo de deslizamiento la fuerza $H_{\mathrm{G}}$ es mucho mayor que la $H$. Por lo tanto, para grandes corrimientos horizontales, los apoyos de neopreno son poco apropiados, ya que en ese caso se requiere un gran espesor, $h$, que es antieconómico o ha de contarse con un gran esfuerzo de retroceso. Además, hay que advertir que la estabilidad lateral del apoyo disminuye con el mayor espesor de neopreno, por lo que las normas BVM (8) (*) prescriben que ese espesor total no ha de exceder del 20 por 100 de la dimensión menor de la planta de apoyo.

(*) $\mathrm{BVM}=$ Ministerio Federal de Comunicaciones.
La rigidez transversal (tangencial) del apoyo varía poco cuando el apoyo está compuesto de varias capas de neopreno; por el contrario, la rigidez contra el giro (o vuelco) aumenta considerablemente. Esta rigidez contra el giro equivale a la resistencia contra un movimiento de giro de la construcción alrededor del eje horizontal que pasa por el apoyo. Como consecuencia aparecen en la placa de neopreno flexiones debidas al momento de giro. La rigidez a la flexión o al giro se define por el momento necesario para producir un ángulo de giro $\varphi=1$ y se deduce de la expresión:

$$
R_{\mathrm{B}}=\frac{J_{\mathrm{G}} \cdot E_{0}}{h}[\mathrm{kp} \cdot \mathrm{cm}]
$$

(fórmula solamente válida para apoyos de una sola capa de neopreno) (fig. 2a), en la que: $J_{G}$ es el momento de inercia del área, en planta, del neopreno, respecto a la línea media.

Sin embargo, la relación [9] sólo es aplicable cuando la dilatación transversal del neopreno puede hacerse sin obstáculo a todo lo largo de su espesor $h$. Cuando se trata de apoyos de varias capas, las chapas de acero que se intercalan dificultan esencialmente las dilataciones transversales de los diferentes neoprenos. Como consecuencia, la rigidez de flexión es considerablemente mayor, y esto se acentúa tanto más cuanto más delgado sea el espesor, $h_{1}$, de cada capa en comparación con su anchura, $b$. Con $b / h_{1}=n$ se tiene la siguiente fórmula para la rigidez de giro de los apoyos de varias capas, debida a A. N. Gent (1):

$$
R_{\mathrm{B}}=\frac{J_{\mathrm{G}} \cdot E_{0}}{h} \cdot \frac{4}{3}\left(1+\frac{k n^{2}}{20}\right)[\mathrm{kp} \cdot \mathrm{cm}]
$$

en que $k$ es, de nuevo, una constante numérica que depende de la dureza Shore (p. ej. $k=0,56$ para $65^{\circ}$ Shore), y $E_{0}$, el módulo de elasticidad según la figura 4 .

Introduciendo, de nuevo, un módulo ideal de elasticidad que dependa de la relación de dimensiones y de la dureza del neopreno

$$
E_{i, \mathrm{~B}}=E_{0} \cdot \frac{4}{3}\left(1+\frac{k n^{2}}{20}\right)[\mathrm{kp} \cdot \mathrm{cm}]
$$

tenemos, en el caso de dilatación transtersal coartada, para la rigidez de flexión, según ecuación [9]:

$$
R_{\mathrm{B}}=\frac{J_{\mathrm{G}} \cdot E_{t \cdot \mathrm{B}}}{h}[\mathrm{kp} \cdot \mathrm{cm}]
$$

Por la [11] vemos que el módulo ideal de elasticidad, para placas delgadas (en comparación con su anchura), crece aproximadamente proporcional al cuadrado de $n$. 
Si para coartar los abultamientos laterales o, también, si para elevar la presión admisible, elegimos espesor de placa, $h_{1}$, muy pequeño, p. ej. que sea solamente $h_{1}=b / 100$, tenemos-con $n=100$, y suponiendo que se trate de una tira larga como apoyo de articulación y que la dureza del neopreno sea de $65^{\circ}$ Shore-, un módulo de elasticidad:

$E_{i \cdot \mathrm{B}}=47 \cdot \frac{4}{3} \cdot\left(1+\frac{0,56 \cdot 100^{2}}{20}\right)=18.000 \mathrm{kp} / \mathrm{cm}^{2} ;$

esto es: aproximadamente 1/15 del módulo de elasticidad del hormigón. En este caso la articulación de neopreno es tan rígida a la flexión como un prisma de hormigón (que tiene resistencia a la compresión y a la tracción) de las mismas dimensiones en planta, pero con un espesor de 15 veces $h_{1}$.

Por lo tanto, la relación $n=b / h_{1}$ no conviene se elija tan grande como en el ejemplo, cuando deba ser pequeño el momento, $M$, necesario para producir un determinado ángulo de giro; y lo mismo ocurre cuando se desea que la excentricidad, $e=M / N$, sea pequeña.

En las articulaciones cortas las circunstancias son algo más favorables, ya que es posible una cierta dilatación tangencial en la misma dirección del eje de giro; este efecto, sin embargo, es menor que el debido a la rigidez de compresión.

La distribución de las cargas normales y tangenciales por debajo de la placa de neopreno, en función del momento de giro, $M_{\varphi}$, ha sido dada por Topaloff en (17). Para los valores corrientes de $n$ en apoyos de varias capas, resultan cargas o tensiones relativamente elevadas, aun para pequeños ángulos $\varphi$ de giro.

Vemos que, en estos apoyos, para las tres clases de solicitación (compresión, fuerza cortante, flexión) se producen deformaciones tangenciales en el neopreno, que pueden tomar grandes valores en los bordes libres. Por lo tanto, debe tenerse euidado con la superposición (o composición) de las cargas. Esto es necesario, especialmente, en caso de solicitaciones duraderas (permanentes) ya que, teóricamente, con presión y giro solamente, resultan cargas tangenciales con corrimientos horizontales que rebasan los admisibles indicados en (8) (o sea, los de las normas BVM ya mencionados).

\section{Apougs de caja fija rellena de neopremo}

\subsection{Primera fase de desarrollo.}

Para elevar la capacidad portante del neopreno sin que disminuya su deformabilidad para los mo- vimientos de giro se han ideado los apoyos de caja rellena de neopreno, que se describen en las referencias bibliográficas (6) y (7) (fig. 6). La placa de neopreno, relativamente gruesa, de planta circular, va metida en una caja de acero y cubierta con una tapa del mismo material, de modo que pueda resistir y transmitir presiones muy elevadas sin que la contracción, $\Delta h$, de compresión sea muy apreciable.

La tapa de acero, lo mismo que el émbolo de una prensa hidráulica, puede efectuar pequeños movimientos verticales y de giro. Por su parte inferior (o sea, por la parte superior de la caja) lleva un anillo de cierre. A diferencia de los apoyos de una o varias capas, la presión centrada produce sobre la superficie de la placa una compresión constante, ya que en ninguna parte puede el neopreno formar abultamientos que dejen de transmitir las fuerzas. En estas condiciones, el neopreno puede compararse a un líquido viscoso.

Por medio de ensayos hechos en el Instituto OttoGraf (Dirección del Prof. Dr. Ing. G. Weil) hemos comprobado que el neopreno (neopreno con aproximadamente $60^{\circ}$ de dureza Shore) permanece inalterado aun con presiones que exceden de los 1.600 $\mathrm{kp} / \mathrm{cm}^{2}$, de modo que son perfectamente admisibles valores prácticos de $400 \mathrm{kp} / \mathrm{cm}^{2}$. La presión del apoyo contra el hormigón, con solicitación de área parcial y buenas armaduras transversales, puede fijarse en $p=300 \mathrm{kp} / \mathrm{cm}^{2}$. Los ensayos ulteriores, con movimientos de giro, se llevaron hasta un límite máximo de $p=400 \mathrm{kp} / \mathrm{cm}^{2}$.

El cierre entre caja y tapa no presenta dificultades de ninguna clase; aun con presiones muy elevadas. Los ensayos demostraron que los anillos metálicos de cierre de la fábrica de máquinas Esslingen, después de algunos miles de giros seguían inalterables y el neopreno de los bordes sólo presentaba en la arista algunos desgastes insignificantes.

Cuando la placa de neopreno está adherida a la tapa y al fondo de la caja de modo que se impidan todos los movimientos, al efectuarse un ángulo de

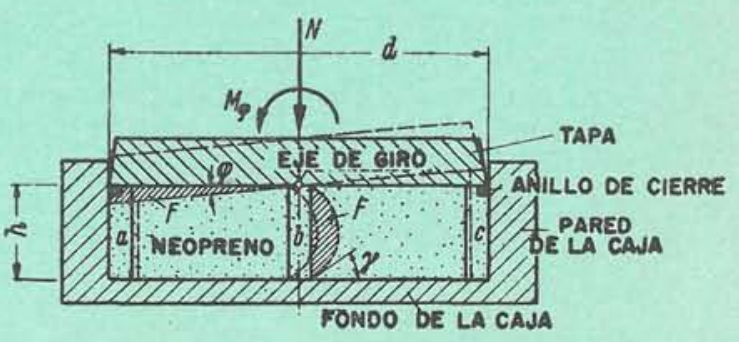

Fig. 6.-Apoyo de caja rellena con placa gruesa de neopreno. Deformación tangencial de los prismas de neopreno en la zona media (b) de la placa. Deformación de compresión (a) y de tracción (c) en los bordes. 
giro, $\varphi$, representado esquemáticamente en la figura 6 , se producen en la placa de neopreno las deformaciones de los prismas, $a, b, c$.

La resistencia contra el giro, o sea, la rigidez de flexión, se debe, principalmente (lo mismo que en los apoyos de capas), a la resistencia contra la deformación tangencial que aquí es máxima en la mitad de la placa.

Si consideramos, solamente, el trabajo de deformación del neopreno, se demuestra fácilmente que la rigidez de flexión depende de la relación de dimensiones y de las constantes propias del material, en la siguiente forma:

$$
R_{\mathrm{B}}=\frac{J_{\mathrm{G}}}{h}\left(E_{0}+\frac{3}{2} G_{0} n^{2}\right)[\mathrm{kp} \cdot \mathrm{cm}]
$$

en que: $J_{G}$ es el momento de inercia de la placa respecto al eje de giro; si $d$ es el diámetro de placa, $J_{\mathrm{G}} \cong 0,05 d^{4} ; n=d / h$ es la relación del diámetro al espesor. Teniendo en cuenta la incompresibilidad del neopreno, encerrado por todas partes, calidad blanda, podemos suponer un coeficiente de dilatación transversal $\mu=0,5$, con lo que se deduce:

$$
E_{0}=2 G_{0}(1+\mu)=3 G_{0}
$$

y de aquí sale la rigidez de flexión:

$$
R_{\text {В }}=0,15 n \cdot G_{0}\left(1+0,5 n^{2}\right) \cdot d^{3}
$$

Introduciendo, una vez más, un módulo ideal que dependa de la relación de dimensiones

$$
G_{i}=G_{0} \cdot n\left(0,15+0,075 n^{2}\right)
$$

se halla para la rigidez de flexión el valor sencillo:

$$
R_{\mathrm{B}}=G_{i} \cdot d^{3}[\mathrm{kp} \cdot \mathrm{cm}]
$$

El momento necesario para que se produzca un giro, $\varphi$, es:

$$
M_{\varphi}=R_{\mathrm{B}} \cdot \varphi=G_{i} \cdot \varphi \cdot d^{3}[\mathrm{kp} \cdot \mathrm{cm}]
$$

Este momento se aumenta algo por el rozamiento del neopreno y del anillo de cierre con la pared de la caja. El movimiento deslizante se extiende solamente a una fracción de altura independiente de $h$, que es desconocida y que estimaremos, aproximadamente, en $\Delta h=1 \mathrm{~cm}$ para $\varphi=0,01$. Designando la carga de compresión de la goma con $p$, y el coeficiente de rozamiento entre neopreno y pared con $\mu_{\mathrm{T}}$, se obtiene el momento suplementario

$$
\Delta M \cong \mu_{\mathrm{T}} \cdot p \cdot \Delta h \cdot d^{2}[\mathrm{kp} \cdot \mathrm{cm}]
$$

Hemos despreciado el rozamiento entre anillo + tapa y la pared de la caja. En la figura 7 se ha representado el momento deducido de [16] y [17]

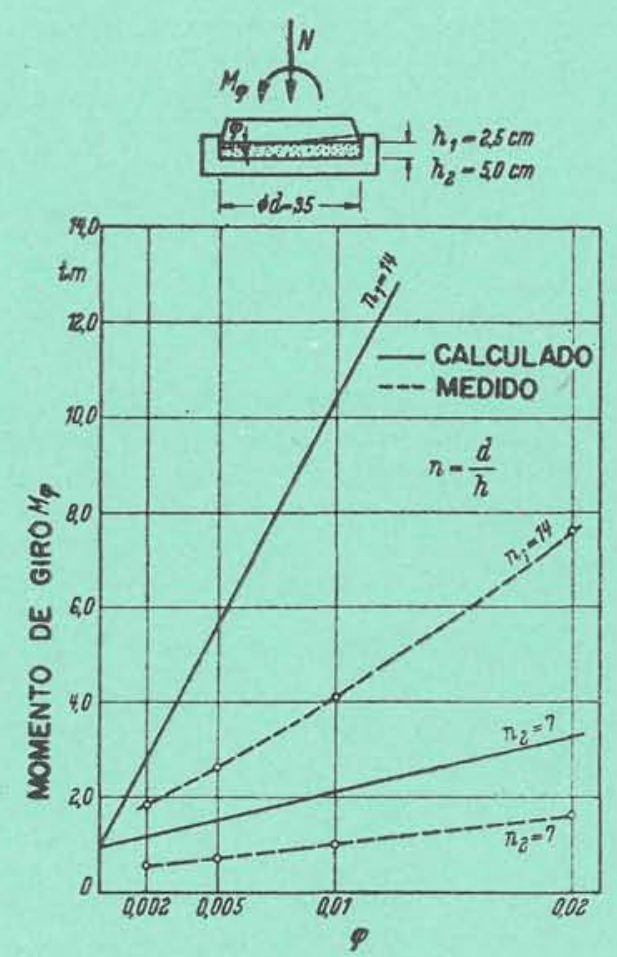

Fig. 7,-Momento, $\mathrm{Mo}$, en función de o y de $\mathrm{n}$. según ensayos y según cálculo.

en función de $\varphi$ para un neopreno de $-60^{\circ}$ dureza Shore. El diámetro de la placa de neopreno es $d=35 \mathrm{~cm}$; su espesor, $h_{1}=2,5 \mathrm{~cm}$, y resp. $h_{2}=5$ centímetros (dos ensayos).

Tenemos: $n_{1}=d / h_{1}=14$ y resp. $n_{2}=7$. Con $G_{0} \cong 11 \mathrm{kp} / \mathrm{cm}^{2}$, la figura 5 nos da para módulo ideal tangencial [14]

$$
G_{i, 1}=11 \cdot 14(0,15+0,075 \cdot 196) \cong 2.250 \mathrm{kp} / \mathrm{cm}^{2}
$$

y, respectivamente,

$$
G_{i, 2}=11 \cdot 7(0.15+0,075 \cdot 49) \cong 290 \mathrm{kp} / \mathrm{cm}^{2},
$$

y con esto, los momentos, $M_{\varphi}$, según [16] para un ángulo de giro $\varphi=0,01$, son:

$$
\begin{gathered}
M_{1, \varphi}=2.250 \cdot 35^{3} \cdot 0,01=9,6 \mathrm{Mp} \cdot \mathrm{m}, \mathrm{y} \text { resp. } \\
M_{2, \varphi}=290 \cdot 35^{3} \cdot 0,01=1,3 \mathrm{Mp} \cdot \mathrm{m}
\end{gathered}
$$

El rozamiento con la pared (que ha de añadirse a lo anterior) suponiendo una presión centrada con carga $p=400 \mathrm{kp} / \mathrm{cm}^{2}$ y $\mu_{\mathrm{T}}=0,20$, según [17] es:

$$
\Delta M=0,20 \cdot 400 \cdot 1 \cdot 35^{2}=98.000 \mathrm{kp} \cdot \mathrm{cm}
$$

Como comprobación de estos cálculos se efectuaron ensayos que dieron como resultado momentos efectivos mucho menores (véase fig. 7). La razón de esta discrepancia es que, en la realidad, no se 
da la adherencia completa del neopreno con el fondo de la caja ni con la tapa, ya que la placa se colocó sencillamente en la caja y, por lo tanto, puede deslizar un poco en ella una vez vencido el rozamiento y, con ello, disminuye la deformación tangencial. Las superficies de acero estaban simplemente torneadas, sin acabado posterior.

En los ensayos se vio también que la magnitud del momento depende mucho de la velocidad con que se introduce la solicitación. Cuando se introducía el ángulo de giro en unos pocos segundos, la fuerza que había de emplearse era mucho mayor que cuando el movimiento se efectuaba con lentitud de giro. Por lo tanto, es un hecho que la velocidad de solicitación desempeña un papel muy importante acerca de lo cual insistiremos más adelante.

La comparación entre el cálculo y las mediciones demuestra que la influencia del espesor de capa sobre la rigidez de flexión queda bien interpretada por la ecuación [15]. Al duplicar el espesor de placa, el momento tanto calculado como medido se reduce aproximadamente en un 25 por 100 .

En los ensayos, la caja tenía $\varnothing 35 \mathrm{~cm}$; la presión total, $N=384 \mathrm{t}$, o sea, $p=400 \mathrm{kp} / \mathrm{cm}^{2}$. Con un ángulo de giro, $\varphi=0,01$, la excentricidad de los momentos medidos, $M_{\phi}$, era:

$$
\begin{array}{cl}
\text { para } n=14 & e_{1}=M_{\varphi} / N=420 / 384=1,1 \mathrm{~cm} . \\
\text { y para } n=7 & e_{2}=, \quad=100 / 384=0,26 \mathrm{~cm} .
\end{array}
$$

Estos valores son muy aceptables por lo reducidos que son. El cálculo hubiese dado valores, aproximadamente, dobles.

\subsection{Segunda fase de desarrollo.}

Apoyos de caja fija, rellena de neopreno, con dispositivo para que la carga quede perfectamente centrada.

El momento de giro (de vuelco) puede aún reducirse, aun tratándose de placas delgadas (valores grandes de $n$ ) o ángulos de giro grandes (p. ej. 0,04). Basta para ello, según se indica en la figura 8 , intercalar entre neopreno y acero dos capas de material deslizante. Con esto queda casi libre el corrimiento horizontal del neopreno y no se precisan deformaciones tangenciales para que se establezca el ángulo de giro. Las deformaciones del neopreno, libres de esa resistencia de rozamiento, se representan esquemáticamente en la figura 8.

También para estos apoyos de caja rellena de neopreno y con capas interiores deslizantes se midieron los momentos y se hallaron para $n=14$ los valores de los ángulos de giro correspondientes hasta

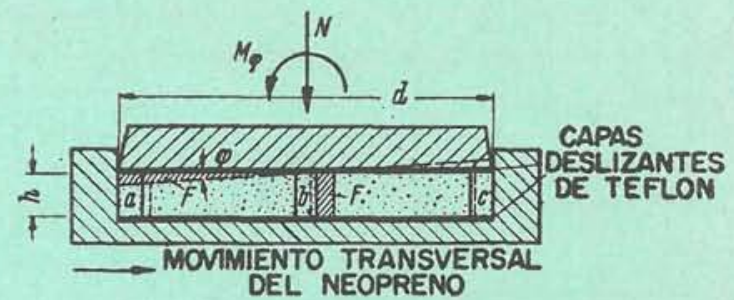

Fig. 8.-Apoyo de eaja fija rellena de neopreno, placa delgada, dos capas de material deslizante. Deformación tangencial del neopreno, nula o insignificante.

$\operatorname{tag} \varphi=0,03$. Para material de las capas deslizantes se utilizó primeramente la pintura (a mano) de disulfito de molibdeno (Molykote) de la que se dio una mano a las superficies superior e inferior de la placa de neopreno. En otros ensayos se utilizaron láminas de $2 \mathrm{~mm}$ de espesor de tetraflúor-etileno (llamado Teflon, de la firma Du Pont, véase 4.2), colocadas también en las partes superior e inferior. Los momentos, $M_{\varphi}$, medidos en ambos casos ( $y$ también sin capa deslizante), se dan en la figura 9 en función del ángulo de giro, $\varphi$. Como ordenadas se han tomado los momentos $M_{\varphi}$ referidos al valor $d^{3}$, es decir, $M_{\varphi} / d^{3}$. Para la comparación, como se ha dicho, se han representado los momentos que se obtienen, cuando no hay capas deslizantes, siempre para $n=14$ (figura 7). Se ve claramente que estas capas-especialmente para grandes ángulos de giro-producen una disminución esencial del valor de los momentos. El Teflon resulta mucho más eficaz que el Molykote. El Teflon, además, es un buen protector contra la corrosión del acero; muy duradero, ya que no se desgasta con los pequeños movimientos, aunque sean frecuentes (véase epígrafe 4,3). Este material debe ser, pues, el preferido.

Una comparación con los apoyos de acero representados en la figura 1 hace ver que para un mismo ángulo de giro $\varphi$, los de caja rellena de neopreno permiten excentricidades mucho menores. Suponiendo una presión de Hertz de $\sigma_{\mathrm{H}}=16 \mathrm{Mp} / \mathrm{cm}^{2}$ (apoyos Corroweld), para transmitir una carga total de $N=384 \mathrm{Mp}$ se precisa (en los de acero) un radio de contacto esférico de $r=156 \mathrm{~cm}$. De aquí se deduce, para un ángulo de giro $\varphi=0,02$, una excentricidad $e=0,02 \cdot 156=3,1 \mathrm{~cm}$. Para el mismo caso, pero con un apoyo de caja rellena de neopreno y con capas deslizantes de Teflon, resulta, según la figura 9 para $\varphi=0,02$, una excentricidad:

$$
e=M_{\varphi} / N=\frac{2,93 d^{3}}{384.000}=0,33 \mathrm{~cm} .
$$

Para superficies de acero sin pulir, los resultados serían más desfavorables.

Como resumen: el empleo de articulaciones de caja rellena de neopreno y capas deslizantes, aun 


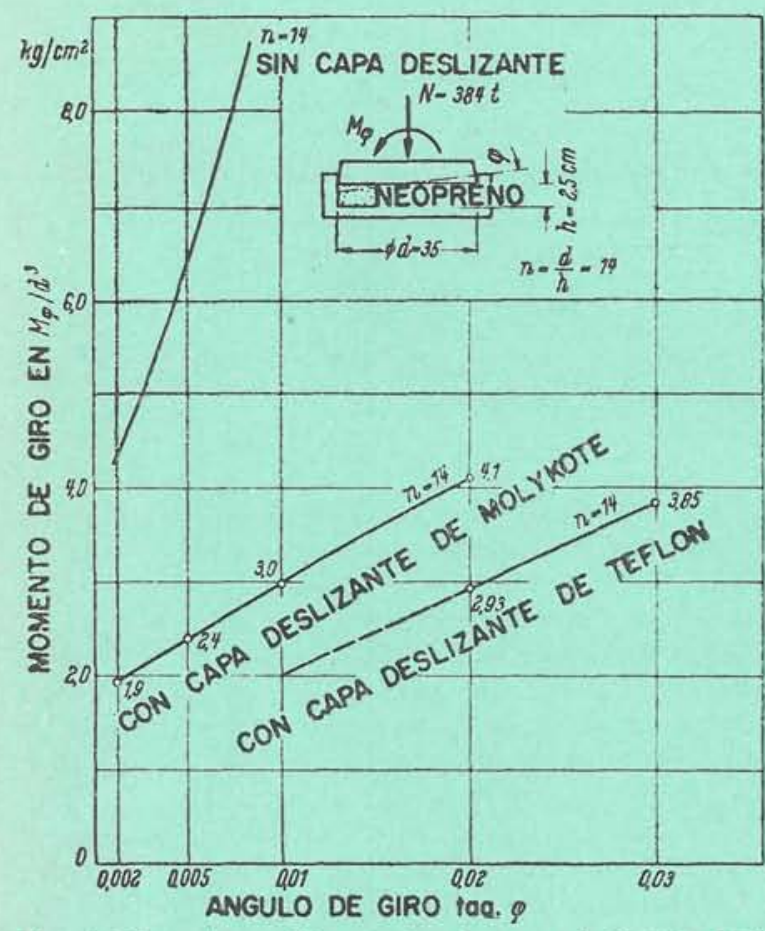

Fig. 9.-Momentos medidos empleando capas deslizantes arriba y abajo de la placa de neopreno:

Diám., $\mathbf{d}=35 \mathrm{~cm}$; espesor, $\mathrm{h}=25 \mathrm{~mm} ; \mathrm{n}=\mathrm{d} / \mathrm{h} \quad 14$; durezs, $60^{\circ}$ Shore; carga repartida, $\sigma=400 \mathrm{kp} / \mathrm{cm}^{3}$; temperatura, $\sim 20^{\circ} \mathrm{C}$; movimiento lento.

para grandes ángulos de giro y placas de poco espesor, la excentricidad es prácticamente despreciable.

Como se ha indicado ya, el momento necesario para producir un determinado giro depende esencialmente de la velocidad de solicitación. Por lo

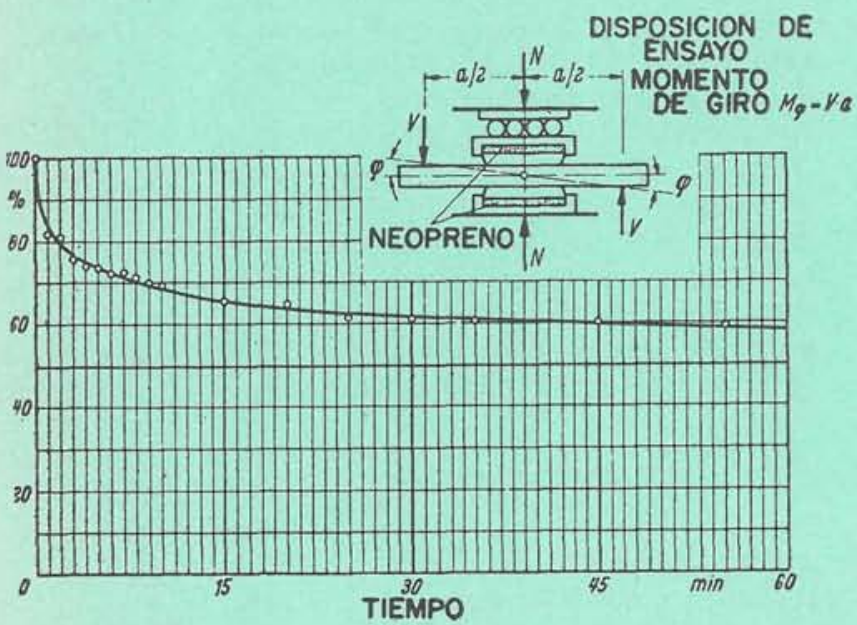

Fig. 10.-Disminución de las fuerzas de vuelco $V$ en función del tiempo, en $\%$ del valor inicial al establecer rápidamente el ángulo de giro $\varphi=0,02$. abajo (Teflon). tanto, se efectuaron ensayos estableciendo el ángulo de giro todo lo rápidamente posible que permitía la instalación-unos pocos segundos-para mantenerlo constante después. El momento inicial introducido debía ir disminuyéndose después de un modo continuo. La amortiguación del momento en función del tiempo se representa en la figura 10. Vemos en ella que, para producir el ángulo de giro $\varphi=0.02$ el momento necesario, o lo que es igual, la fuerza excéntrica necesaria para producirlo (con las mismas dimensiones $d=35 \mathrm{~cm} ; n=14$, capas deslizantes de Molykote) después de $60 \mathrm{mi}-$ nutos se había reducido al 59 por 100 del valor inicial. Como se ve en la curva 10 sigue rebajándose el momento con el transcurso del tiempo, hasta un valor final ya constante que es el 50 por 100 aproximadamente del valor inicial. Esto tiene su explicación en los pequeños deslizamientos que se producen y en el comportamiento algo plástico del neopreno. Para estos apoyos de caja rellena de neopreno, estos efectos son favorables, pues la rigidez al giro con los movimientos lentos es más pequeña como por ejemplo sucede con los debidos al cambio de temperaturas. No se produce aumento de la contracción vertical $\Delta h$. Tampoco hacen falta neoprenos de alta calidad (poco plásticos) como los que se necesitan en los apoyos de placas de neopreno (figuras $2 \mathrm{a}$ y $2 \mathrm{~b}$ ).

Llamamos la atención sobre el hecho de que la adaptabilidad del neopreno a la deformación va disminuyendo cuando baja la temperatura. Según datos de Jörn (3) relativos al neopreno, debe contarse con un aumento del módulo de $E$ dado por la figura 4 , de 100 por 100 cuando la temperatura baja de $20^{\circ} \mathrm{C} \mathrm{a}-30^{\circ} \mathrm{C}$. Valores análogos han sido dados por K. E. Ott en (5). La figura 11 representa (abscisas hacia la izquierda) el aumento de $E$ (en realidad se ha representado el valor relativo) para una determinada clase de neopreno, cuando va disminuyendo la temperatura. El valor de compara-

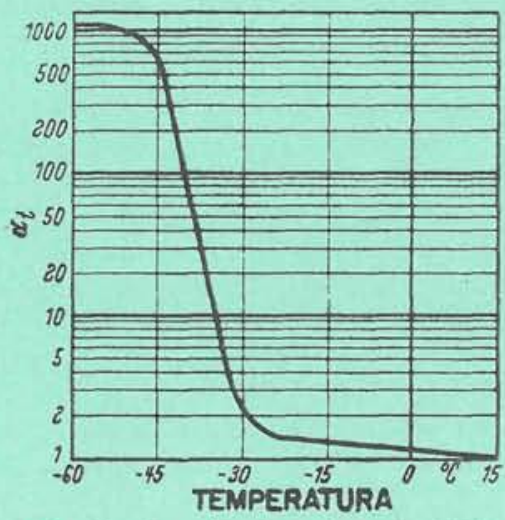

Fig. 11.-Dependencia entre el módulo relativo de elasticidad y la temperatura en el neopreno $\mathrm{E}_{t}=\mathrm{E}_{15}, a_{t} ; \mathrm{E}_{15}=$ módulo de elasticidad a $15^{\circ} \mathrm{C}$, según ensayos de K. E. Ott. 
ción es $E_{15}$, o sea, el valor que tiene $E$ a $15^{\circ} \mathrm{C}$. Vemos en la figura que este valor de $E$, a partir de $-30^{\circ} \mathrm{C}$ hacia abajo, aumenta muy rápidamente; a $\operatorname{los}-40^{\circ} \mathrm{C}$ su valor es 80 veces el de $E_{15}$. La figura 11 indica esta curva cuya marcha depende esencialmente de la composición del neopreno, es decir, de los añadidos que se le incorporan en su fabricación, de modo que es posible fabricar diversas clases o calidades adaptadas a las bajas temperaturas. De la figura 11 se deduce que a $-30^{\circ} \mathrm{C}$ los momentos serán el doble que a la temperatura del verano. Pero como la excentricidad--como vimos más arriba-es muy pequeña, el aumento de los momentos debido a temperaturas bajas, aun siendo del orden de 100 por 100 a 200 por 100 , no tiene importancia en la mayoría de los casos prácticos.

Con apoyos de caja rellena de neopreno pueden también transmitirse juerzas horizontales considerables mediante anclajes adecuados que se sujetan a la caja o a la tapa. Esta última se aprieta lateralmente contra la pared de la caja que debe estar convenientemente pulida y endurecida. Cuando la fuerza horizontal actúa perpendicularmente al eje de giro, el rozamiento produce un momento suplementario:

$$
\Delta M_{\mathrm{H}} \cong \mu \cdot \frac{H \cdot d}{2}
$$

Por medio de ensayos pudo comprobarse que, puliendo las superficies deslizantes o dándoles una mano de Molykote, para fuerzas horizontales de hasta $H=0,20 \mathrm{~N}$ el coeficiente de rozamiento entre tapa y pared de caja era inferior a $\mu=0,01$. Si la fuerza horizontal actúa paralelamente al eje de giro, el momento $\Delta H$ es aún menor. En general, las fuerzas horizontales actúan eventualmente, es decir: no suelen coincidir con los movimientos de giro; en este caso, la comprobacićn se limita al cálculo de la presión lateral.

Los apoyos de caja rellena de neopreno se han empleado ya en muchos casos, p. ej., en puentes de Düsseldorf, puente sobre el Rin en Schierstein y en un puente de ferrocarril en Suiza.

La figura 12 representa el mayor tipo de apoyo de esta clase, construido hasta la fecha. Los datos principales se dan en el pie de la figura. Como se ve en la foto, la placa se compone de varios trozos. $\mathrm{El}$ apoyo fue destinado a un establecimiento industrial situado en terreno movedizo.

En la construcción de puentes se presenta con frecuencia el caso de apoyos que no solamente deben transmitir esfuerzos de compresión, sino también, a veces, de tracción; por ejemplo, cuando la sobrecarga es lateral, como puede suceder en puentes muy anchos, con apoyos de pequeñas dimensiones.

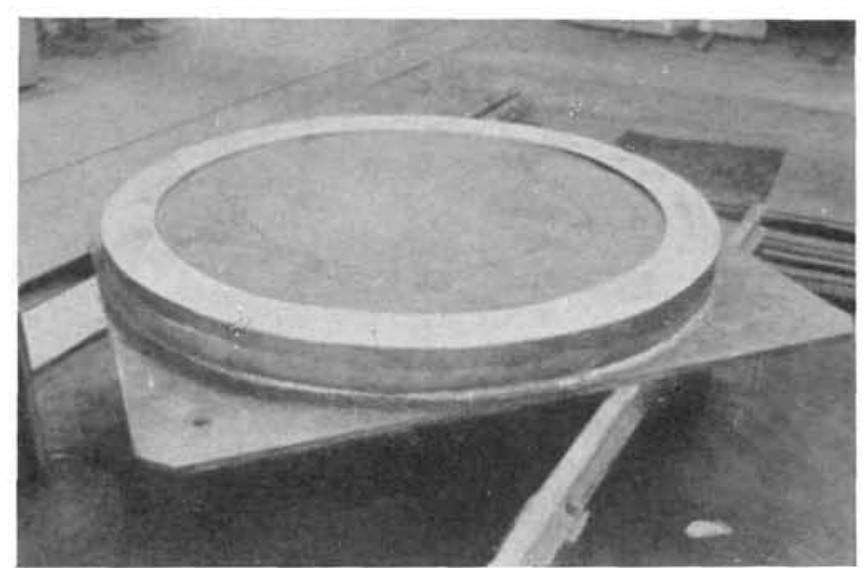

Fig. 12.-Apoyo de caja rellena de neopreno, de la fábrica de Esslingen; sobrecarga o potencia $=5.000 \mathrm{Mp}$; $\varnothing$ interior de caja $=180 \mathrm{~cm}$; espesor de la placa de neopreno, $\mathrm{h}=14 \mathrm{~cm}$. (Fábrica de máquinas Esslingen, sección de fotografías VW, foto n. $^{\circ} 27.794$.)

En la figura 13 se da una solución de apoyo de esta clase, que resiste a la compresión y a la tracción. Al efecto, para absorber las fuerzas de tracción se dispone una barra de anclaje que atraviesa verticalmente todo el apoyo. Una envolvente (vaina) tubular de acero compuesta de dos trozos

separados, evita que el neopreno penetre en el agujero de paso de la barra. Uno de los trozos va unido a la tapa (que aquí ocupa la parte inferior); el otro va unido a la caja (aquí parte superior) de modo que en las líneas de unión no hace falta cierre de impermeabilización. La pequeña ranura que queda entre los dos trozos de la vaina de acero va rodeada de un anillo, también de chapa de acero. $\mathrm{Si}$ la tapa gira un poco respecto del suelo (a consecuencia de una tracción, algo oblicua) se produce a la altura de la ranura una pequeña desviación; para evitar cargas o tensiones locales, la barra de enclaje va rodeada de otra envolvente (vaina) de plástico. Gracias a la elasticidad de este último material, la barra puede efectuar su movimiento de flexión en toda la altura del apoyo. Como los ángulos de giro son pequeños (en general $<1 / 200$ ), las cargas de flexión, en la zona del apoyo, son también muy moderadas. Estas cargas de flexión aún podrían reducirse poniendo, en vez de barra, cable de anclaje formado con alambres, al que pueden darse tensiones previas (pretensado) que neutralicen, en todo o en parte, los esfuerzos que transmita la construcción, y así el apoyo puede alcanzar gran resistencia a la tracción.

En la figura 13 (a la derecha) se ha representado una variante de este dispositivo. Los dos trozos de la vaina de acero que rodean a la barra de anclaje llevan labradas sus caras internas en forma de superficies esféricas con radios $\mathrm{R}$. El pequeño giro de la barra producido por la flexión se establece sin dificultad adaptándose la barra a dichas superficies. 


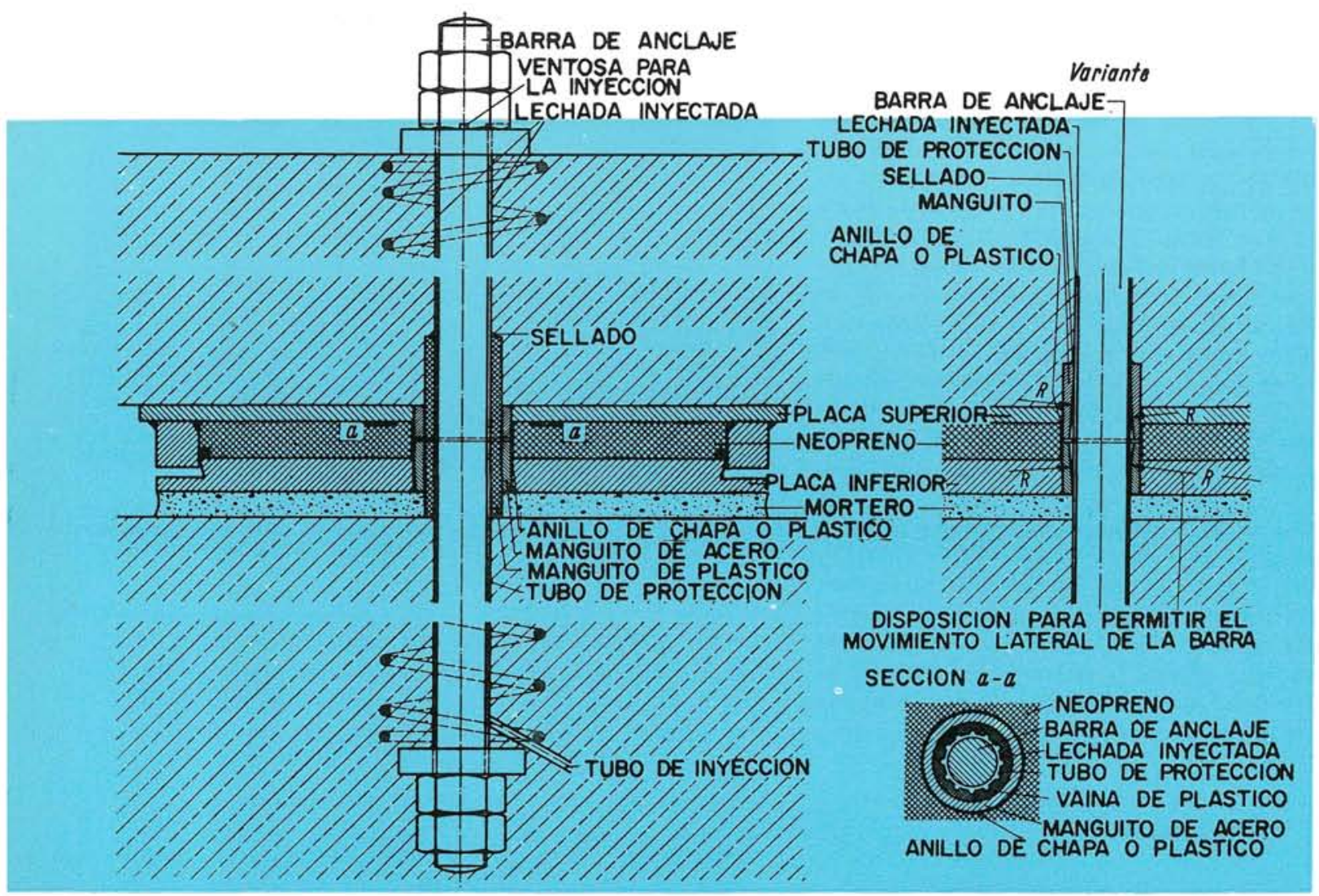

Fig. 13.-Apoyo de caja rellena de neopreno, resistente a tracción y compresión.

En esta variante no hace falla poner vaina flexible de plástico.

\section{Apoyos móviles ale caja rellena de neopreno con capas deslizantes de Tefllom}

\subsection{Generalidades.}

Para aprovechar las ventajas de los apoyos de caja rellena de neopreno, en el caso de que convenga que puedan tener desplazamiento horizontal, se ha ideado combinarlos con apoyos deslizantes: corrientes, de rodillos, de bolas (un ejemplo es el representado en la figura 14). Con esta última disposición se obtienen ventajas para las partes metálicas, ya que la placa de rodadura puede hacerse de menor grueso y, además, el repario uniforme de las presiones sobre los rodillos o las bolas queda garantizado por la placa de neopreno.
En el epígrafe 4.4 describiremos algunos tipos característicos de estos apoyos mixtos, que pueden llamarse «apoyos deslizantes con caja rellena de neopreno».

Los apoyos puramente deslizantes (sin bolas ni rodillos ni neopreno) son conocidos desde hace muchos años, aplicados en puentes y edificios. Sin embargo, nunca alcanzaron gran boga, pues el rozamiento deslizante puede producir esfuerzos grandes

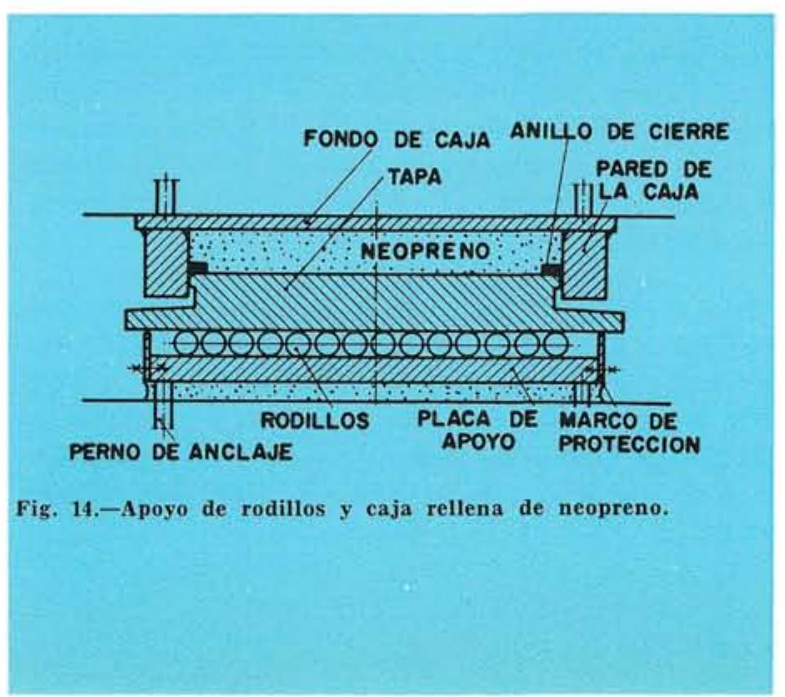


e irregulares, de difícil control, esfuerzos que debían absorberse por la propia superestructura o por la infraestructura y terreno de apoyo, y en ambos casos produciendo efectos perturbadores.

En estos apoyos puramente deslizantes, con un acabado esmerado de las superficies deslizantes, con el empleo de lubricantes y manteniendo presiones moderadas puede conseguirse, en apoyos pequeños, coeficientes de rozamiento que no exceden de $\mu=0,10$, sin llegar nunca a conseguir los valores reducidos del rozamiento de rodadura. En estos últimos, con acero normal duro y presiones de Hertz no muy elevadas, se llega aprox. a $\mu=0,01$ y aún menos con superficies deslizantes endurecidas.

En los grandes apoyos exclusivamente deslizantes es muy difícil conseguir que las superficies de contacto sean perfectamente planas y resulte así completa uniformidad en el reparto de presiones. Las dos superficies deslizantes llegan al contacto en algunas zonas donde se originan presiones locales elevadas que, a pesar de los lubricantes, son causa de que se produzcan desgastes, y el coeficiente de rozamiento aumenta de un modo considerable. Con dispositivos especiales de película de aceite a presión pueden atenuarse estos inconvenientes, pero son demasiado caros y excesivamente delicados para su empleo en las construcciones.

Por otra parte, los apoyos exclusivamente deslizantes, desde el punto de vista constructivo, son los más sencillos y económicos, sobre todo para trasladar grandes pesos con movilidad horizontal en todos los sentidos, porque, en general, se tiende a evitar que, sobre los apoyos, actúen esfuerzos de flexión. Es, pues, indispensable tratar de rebajar, en lo posible, el coeficiente de rozamiento.

\subsection{El Teflon como material deslizante.}

Como se dijo ya en 3 , el Teflon se conoce desde hace algunos años. Se trata de un material sintético (artificial) de tetraflúor-etileno, que reúne condiciones ideales para apoyos de deslizamiento. En primer lugar, cumple las. condiciones indispensables de inalterabilidad y duración. Es notable observar que este material fue elaborado como medio resistente contra los agentes químicos; más tarde se llegó a la conclusión de que tenía propiedades deslizantes muy favorables.

La fabricación inicial data de hace unos quince años y procede del laboratorio de investigaciones de la firma «E. I. Du Pont de Nemours y Cía.» (16), con la denominación de Teflon. Después se ha fabricado en otras partes y con distintos nombres: Hostaflon (Höchst), Fluon (I C. I.). Es resistente contra la acción de los ácidos, álcalis, bencinas, benzoles, hidrocarburos clorados y soluciones diversas inorgánicas y orgánicas, incluso a temperaturas altas. Unicamente le atacan los metales alcalinos fundidos y el flúor a presión. Posee una resistencia extraordinaria contra los efectos de la temperatura (de $-200^{\circ} \mathrm{C} a+300^{\circ} \mathrm{C}$ ), su constante dieléctrica es muy elevada, es incombustible y prácticamente no absorbe agua ni humedad (anti-higroscópico). Así se explica su gran resistencia contra los agentes atmosféricos: algunas muestras, en Florida, expuestas a la intemperie durante siete años, estaban completamente inalteradas.

Las características físicas del Teflon son las siguientes:

Peso específico: 2,1 a $2,3 \mathrm{p} / \mathrm{cm}^{3}$

Coeficiente térmico de dilatación: $3,05 \cdot 10^{-5}{ }^{\circ} \mathrm{C}$

Coeficiente de conductibilidad térmica: $0,2 \mathrm{kcal} /$ $/ \mathrm{m} \cdot \mathrm{h} \cdot{ }^{\circ} \mathrm{C}$

Resistencia a la rotura tracción: 150 a $250 \mathrm{kp} / \mathrm{cm}^{2}$

Dilatac. mecánica a temp. de la hab. : 100 a $200 \%$

Módulos de elasticidad:

Teflon puro: $4.000 \mathrm{kp} / \mathrm{cm}^{2}$

Teflon con añad. (grafito, Molikote) $\sim 6.500$ $\mathrm{kp} / \mathrm{cm}^{2}$

Fibras de Teflon: $\sim 30.000 \mathrm{kp} / \mathrm{cm}^{2}$

Bajo presiones muy elevadas, el Teflon experimenta deformaciones plásticas que se amortiguan al cabo de cierto tiempo y pueden rebajarse considerablemente mediante diversos añadidos (grafito, Molikote, fibras de vidrio).

El Teflon se trabaja con gran facilidad. Con él se fabrican: placas, láminas, barras, tubos de grande y pequeño diámetro, tejidos, cintas de cierre o impermeabilidad, envolventes y forros, etc.; debido a sus excelentes propiedades contra los ataques químicos y a su resistencia térmica y mecánica ocupa hoy, en la técnica, un papel de destacada importancia.

\subsection{Ensayos de Teflon en apoyos deslizantes.}

Para apoyos de construcción nos interesan, especialmente, sus propiedades deslizantes y su resistencia al desgaste. Por iniciativa del autor, en el año 1960 se efectuaron ensayos y mediciones en el laboratorio oficial de la Escuela Politécnica de Stuttgart, bajo la dirección del profesor doctor ingeniero habilitado Wellinger. El dispositivo de ensayos se representa en la figura 15.

En primer lugar se estudió qué clase de materiales convenía poner en contacto para que el roza- 


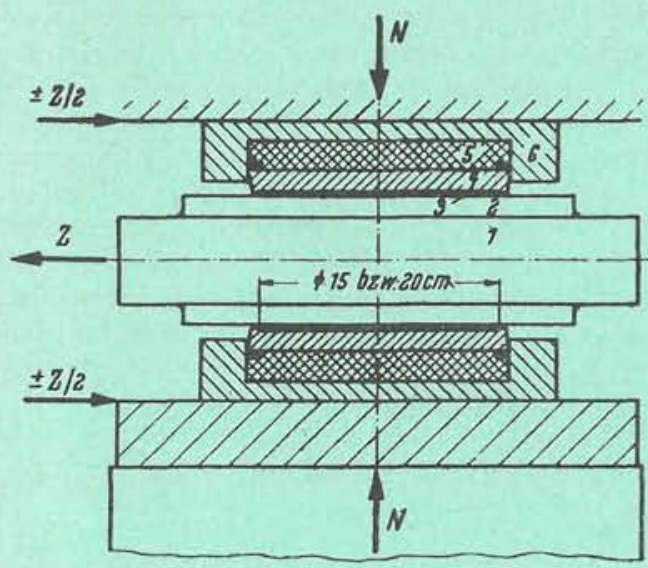

Fig. 15.-Dispositivo de ensayos para mediciones de rozamiento.

miento fuese mínimo. Se vio que el Teflon sobre acero pulimentado no reunía las mejores condiciones presumibles. Un lubricado y recubrimiento suplementario, por ejemplo con Molikote, empeoraba las buenas condiciones deslizantes del Teflon. Los mínimos coeficientes de rozamiento se obtuvieron con Teflon (blanco, fabricado con añadido de bisulfito de molibdeno) sobre una placa de acero recubierta de poliamida. Esta mano de poliamida tenía l a $2 \mathrm{~mm}$ de espesor y servía, al mismo tiempo, de protección de la placa de acero contra la corrosión. Resultados igualmente favorables se obtuvieron con Teflon (blanco) sobre placa endurecida al cromo y pulida. Los valores de los coeficientes o índices de rozamiento medidos en este ensayo están repre-

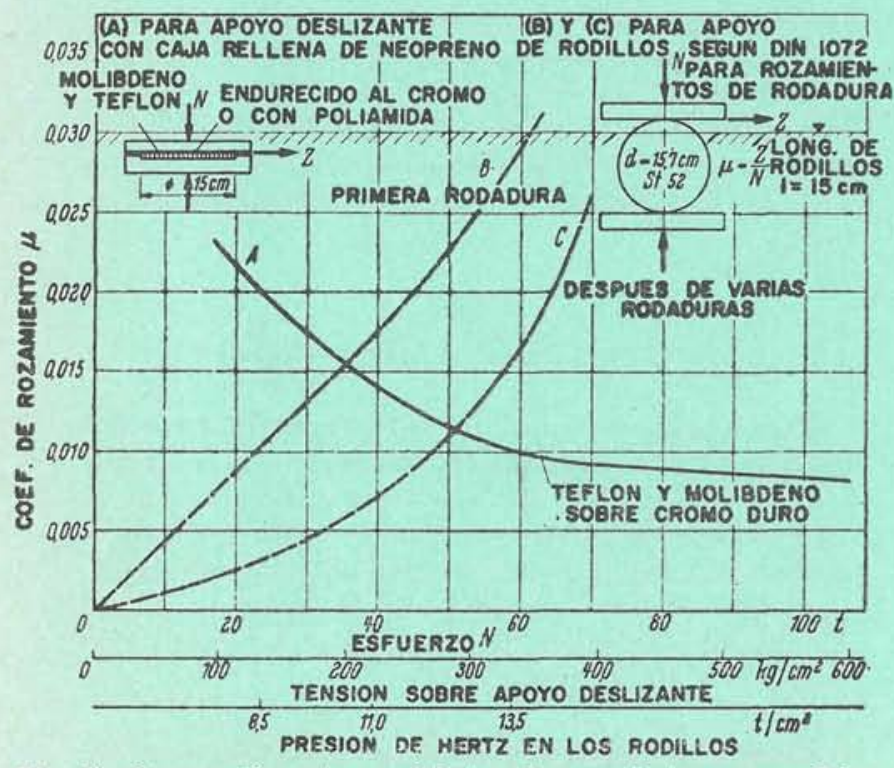

Fig. 16.-Comparación entre coeficientes de rozamiento en superficies deslizantes y con rodillos, en función de la solicitación. sentados en la figura 16 (curva A), en función de la presión ejercida sobre las dos placas deslizantes $p=N / F_{t}$. Para $p=100 \mathrm{kp} / \mathrm{cm}^{2}$ vale $\mu=0,022, \mathrm{y}$ al aumentar la presión va disminuyendo $\mu$ considerablemente, y así, para $p=500 \mathrm{kp} / \mathrm{cm}^{2}$, se midió $\mu=0,008$. Otros ensayos paralelos dieron como resultado valores aún menores, hasta 0,005. Estos índices de rozamiento $\tan$ bajos y para presiones $\tan$ altas hubiesen parecido imposibles hace pocos años.

En la figura 16, y para que sirva de comparación, se han representado también los coeficientes de rozamiento a la rodadura, en apoyos de rodillos (acero), obtenidos con nuevos ensayos realizados por Wellinger y también expresados en función de la solicitación (presión) (curva B). En este caso, los coeficientes de rozamiento aumentan con la presión de Hertz, pues con las altas presiones se produce una deformación plástica en las zonas de rodadura. Como consecuencia de esa deformación y de la rodadura, se produce un endurecimiento del material y los coeficientes de rozamiento bajan de nuevo y llegan a alcanzar los de la línea C. Si, por cualquier causa, los rodillos rebasan o salen un poco de la zona de rodadura, el coeficiente de rozamiento aumenta muy sensiblemente, porque la rodadura ha producido un pequeñísimo reborde que perturba el movimiento. Este efecto de reborde no se observó en los ensayos hechos con Teflon y placas de acero, con recubrimiento o sin él.

Las mediciones efectuadas en ambos ensayos (apoyos deslizantes y de rodillos) se dan en la figura 16. La longitud de los rodillos y el diámetro de los mismos fue, en los ensayos, igual al diámetro de la placa deslizante de Teflon. Con rodillos de acero calidad 52, y para transmitir cargas equivalentes a las admisibles en los apoyos de caja rellena de neopreno, hubo que poner rodillos de longitud 1.5 veces mayor para que su diámetro fuese igual al de la placa deslizante, y para no rebasar la presión admisible de Hertz.

Pudo observarse un fenómeno inesperado: los coeficientes de rozamiento, en el Teflon, disminuyen al decrecer la velocidad. La figura 17 representa los resultados obtenidos que. en parte, están tomados de una publicación americana (16). Esta curiosa propiedad se verifica para todas las solicitaciones. Para los coeficientes de rozamiento dados en la figura 16 , la velocidad de deslizamiento fue de unos $0,10 \mathrm{~mm} / \mathrm{s}$. Si se piensa en los corrimientos que tienen los apoyos de los puentes, con los cambios de temperatura, sus velocidades de deslizamiento serán seguramente mucho menores $\mathrm{y}$, por lo tanto, más pequeños los índices de rozamiento.

Los rozamientos mínimos se dan con presiones muy elevadas y con velocidades muy pequeñas. 


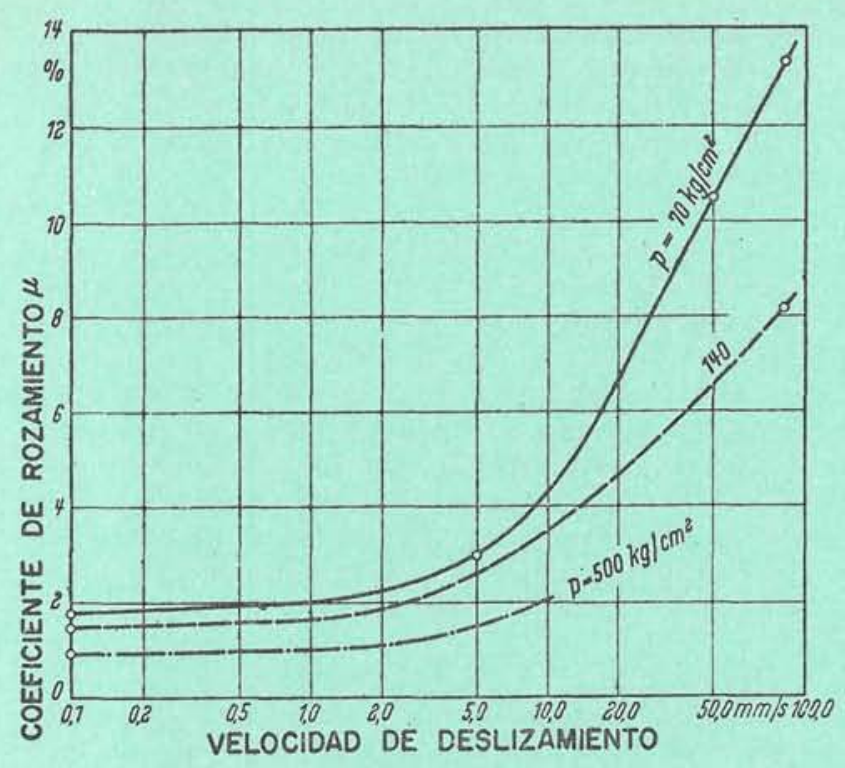

Fig. 17.-Coeficientes de rozamiento $\mu$ para Teflon y cromo-duro, en función de la velocidad de deslizamiento.

Desde $1 \mathrm{~mm} / \mathrm{s}$ a $0,1 \mathrm{~mm} / \mathrm{s}$ no pudieron observarse diferencias apreciables.

Como en todos los procesos de deslizamiento, el valor de $\mu$ es mayor cuando se pasa del reposo al movimiento; una vez iniciado el movimiento, el valor baja $y$, luego, permanece constante durante el movimiento uniforme. La figura 18 nos muestra el esfuerzo de tracción que debe aplicarse a la placa intermedia en función del camino de deslizamiento, siendo los materiales pareados el Teflon blanco y el cromo de endurecimiento; la presión era de $100 \mathrm{kp} / \mathrm{cm}^{2}$. Este par de materiales no dio los coeficientes de rozamiento más favorables; sin embargo, las mediciones hechas dan perfecta idea de la relación que existe entre la fuerza de tracción, $Z$, y el coeficiente de rozamiento, $\mu$. La fuerza $Z_{A}$ necesaria para producir el movimien- to inicial corresponde a un índice de rozamiento inicial $\mu_{A}=4,2$ por 100 ; la $Z_{A}$ es un 50 por 100 mayor que la $Z$ necesaria para mantener el movimiento uniforme, para el que $\mu=2,8$ por 100 . Esto vale para la primera medición; al repetir el experimento (segunda y tercera mediciones) los resultados van mejorando; en el segundo ensayo, el valor inicial, $\mu_{\mathrm{A}}$, es tan sólo 10 por 100 mayor que el $\mu$, que corresponde al movimiento uniforme, y este valor es el mismo que se obtuvo en la primera medición.

El valor inicial, $\mu_{\mathrm{A}}$, que se ha reducido del primero al segundo ensayo, puede conseguirse, prácticamente, en el taller, antes de instalar el apoyo en obra.

También se comprobó que al repetir los movimientos de vaivén de la placa, tanto el rozamiento inicial, $\mu_{\mathrm{A}}$, como el normal, $\mu$, decrecen, $y$ al cabo de unas cien repeticiones llegan a su valor mínimo; la relación $\mu_{\mathrm{A}} / \mu$ permanece prácticamente constante.

En la figura 19 se ha representado la variación de $\mu$ en ensayos hechos con Teflon. Las superficies deslizantes de la placa intermedia llevaban un recubrimiento de poliamida (ver parte superior de la figura 19). Con una presión de $300 \mathrm{kp} / \mathrm{cm}^{2}$ se obtuvo en el primer movimiento $\mu_{\mathrm{A}} / \mu=1,16$; después de 500 movimientos de vaivén y con un recorrido total de unos $30 \mathrm{~m}$, esa relación bajó hasta $\mu_{\mathrm{A}} / \mu=1,10$, y ya, en adelante, permaneció constante. Con presiones de $500 \mathrm{kp} / \mathrm{cm}^{2}$ los resultados fueron $\mu_{\mathrm{A}} / \mu=1,30$ y 1,14 , respectivamente, y se midió un coeficiente, $\mu=0,0056$, que llama la atención por su extraordinaria pequeñez.

Hemos de advertir que estos ensayos duraron una semana y se realizaron durante el día; por la noche se quitaba la solicitación para reanudarla al día siguiente. Como consecuencia de una serie de ensayos, aún no terminada, se entrevé que la relación

Fig. 18.-Esfuerzo de tracción en funciốn del camino recorrido por la placa intermedia. Materiales: Teflon (blanco) $y$ acero con superficie endurecida al cromo. Presión, $\mathrm{p}=100 \mathrm{kp} / \mathrm{cm}^{2}$.
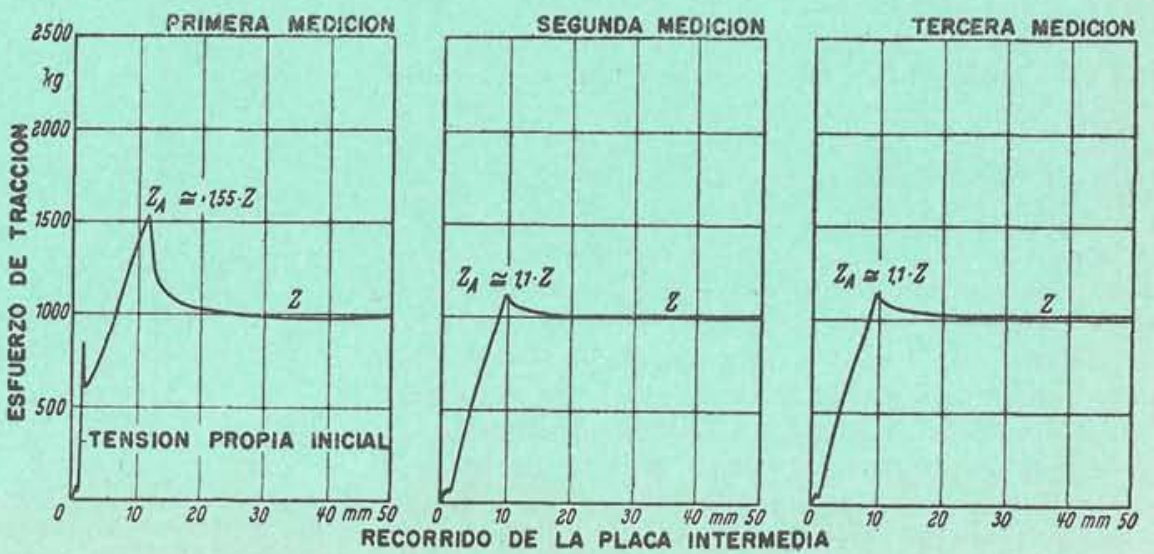

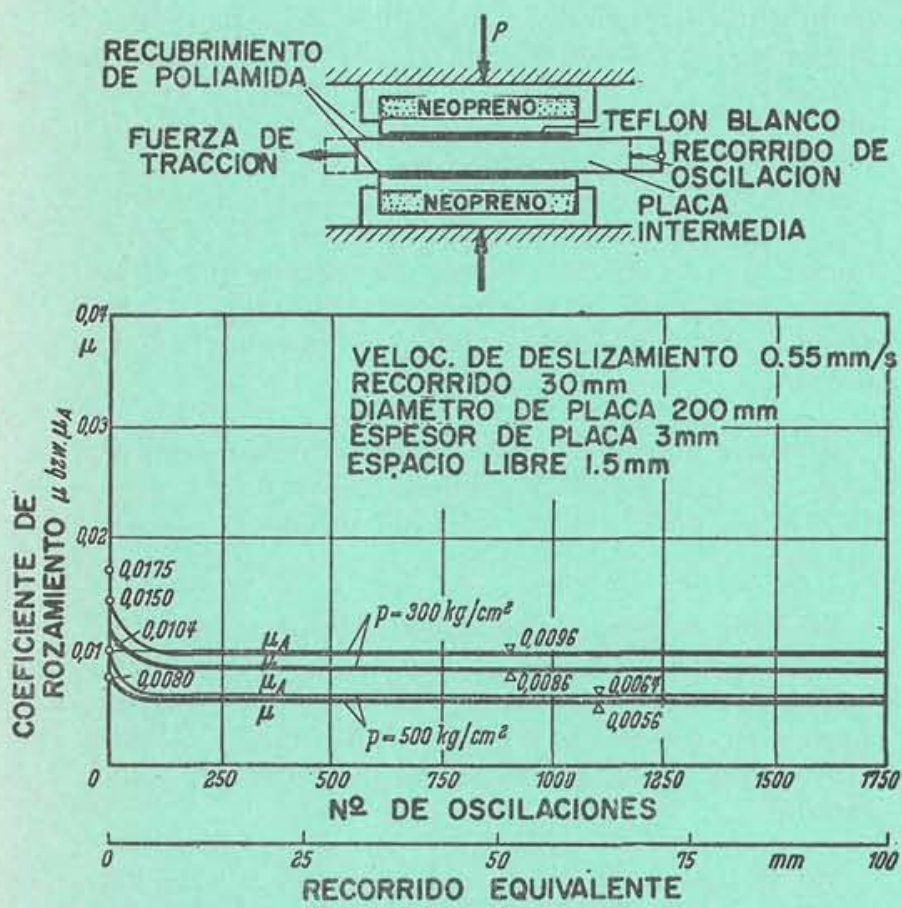

Fig. 19.-Coefieientes de rozamiento en función del número de vaivenes, o sea del camino recorrido, con $p=300$ y $500 \mathrm{kp} / \mathrm{cm}^{2}$.

$\mu_{\mathrm{A}} / \mu$ tiende a valer la unidad cuando la solicitación es permanente, como sucede en los apoyos de los puentes.

El gran número de ensayos efectuados se hizo, principalmente, para determinar la resistencia al desgaste del Teflon. Después de 1.750 movimientos, con un recorrido total de unos $100 \mathrm{~m}$, se interrumpió el ensayo: mediante pesadas cuidadosas de las placas de Teflon pudo comprobarse que no se había producido ningún desgaste. El resultado es sorprendente, ya que el Teflon puro (blanco) empleado tiene, más bien, apariencia de blando, si se le compara con el Teflon fabricado con añadidos. La velocidad de deslizamiento fue de $0,55 \mathrm{~mm} / \mathrm{s}$, o sea, cinco veces mayor que la de los ensayos de la figura 16. El disco de Teflon tenía $3 \mathrm{~mm}$ de espesor, iba embutido en la tapa con $1,5 \mathrm{~mm}$ de profundidad, con lo que quedaba un espacio libre (ranura) de otros $1,5 \mathrm{~mm}$. Por esa ranura el Teflon podía expansionarse unos $0,5 \mathrm{~mm}$, debido a su deformabilidad plástica. No se observaron variaciones de tamaño de ranura. También se hicieron ensayos con discos de Teflon cerrados lateralmente por completo y sometidos a presiones muy elevadas. De ellos se dedujo que tanto la profundidad de embutido como anchura de ranura en el apoyo representado en la figura 20 eran las suficientes para limitar la deformación plástica del Teflon. A pesar de tratarse de un Teflon relativamente blando, no se produjeron abultamientos externos anormales. Con Teflon de añadidos de grafito o de sulfito de molibdeno no se apreciaron indicios de deformación plástica, después de ensayos de bastante duración. Sobre este particular, el laboratorio oficial debe aún informar con carácter definitivo.

Los ensayos han demostrado, de un modo concluyente, que la resistencia al desgaste, cuando los movimiento son lentos, es extraordinariamente elevada y que incluso con el Teflon puro, de pequeño espesor y sometido a presiones altas, la duración y estabilidad son satisfactorias. Para apoyos deslizantes son suficientes las placas relativamente delgadas. Una pequeña plasticidad es, incluso, conveniente para compensar las pequeñas rugosidades y hacer que las superficies deslizantes se mantengan en contacto en toda su área.

En definitiva: el Teflon es un material que posee las condiciones ideales que se requieren en los apoyos deslizantes solicitados a gran presión: índice pequeño de rozamiento, duración, resistencia a la corrosión y estabilidad a altas presiones.

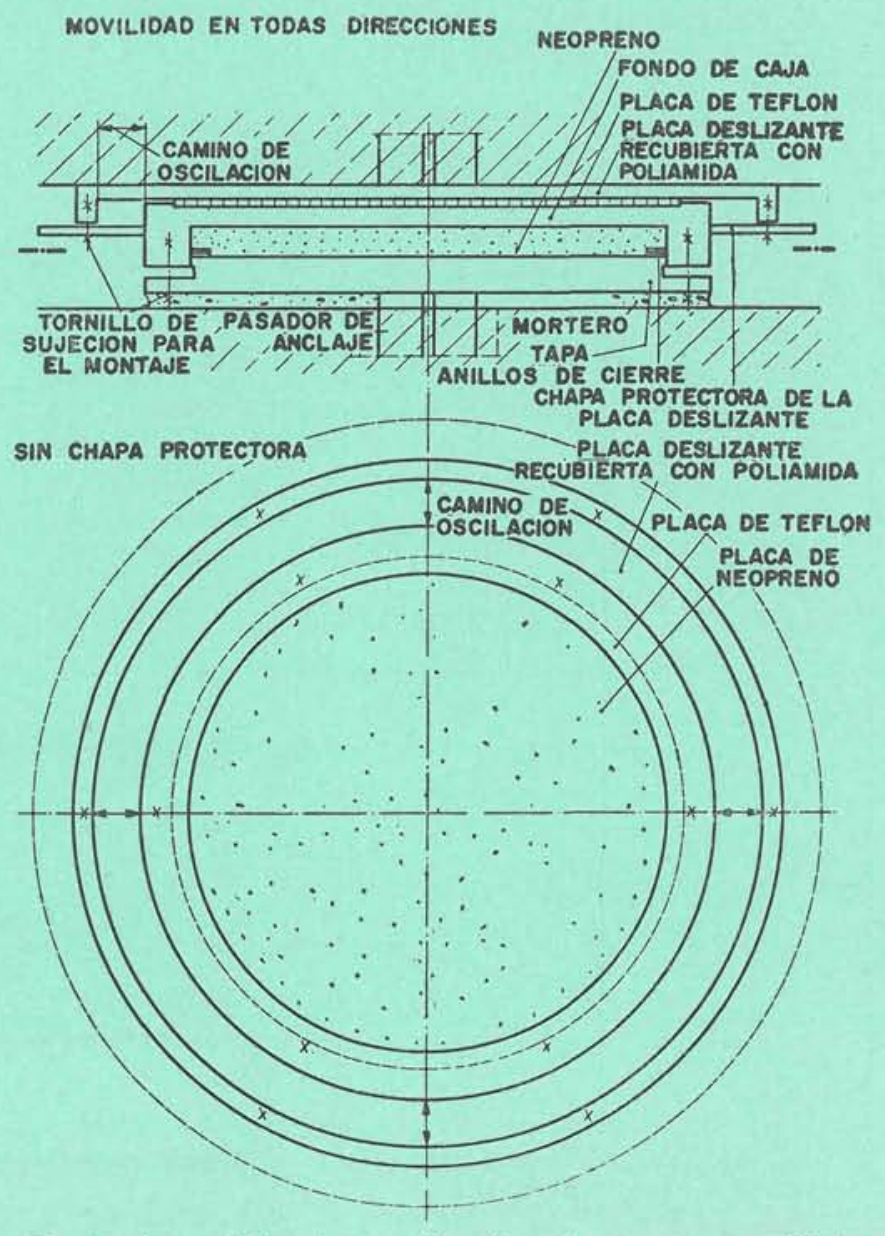

Fig. 20.-Apoyo deslizante con caja rellena de neopreno; movilidad en todas las direcciones. 
4.4. Dispositivos constructivos de los apoyos deslizantes con caja rellena de neopreno.

La figura 20 da un ejemplo de combinación de una articulación de caja rellena de neopreno y una placa deslizante de Teflon, con movilidad en todas direcciones. El disco de Teflon tiene $3 \mathrm{~mm}$ de espesor y va embutido en una mitad de su espesor en el fondo de la caja (que aquí es la parte superior, o sea, el techo). Modernamente, el Teflon suele adherirse a dicho fondo dando rugosidad a la superficie de acero. La superficie deslizante del acero queda abierta hacia abajo para que no se acumule el polvo o la suciedad; además, queda por encima protegida con una chapa. Lleva también un recubrimiento de cromo o poliamida. Este último material es muy recomendable porque se pule fácilmente, es muy tenaz y buen protector contra la corrosión. Con esta disposición no son de temer perjuicios de ensuciamiento $y$ de corrosión que puedan perjudicar a las propiedades deslizantes del apoyo. En la mayor parte de los casos, no hace falta protección lateral, por ejemplo: con bandas de neopreno.

La figura 21 representa, como antes, un apoyo deslizante y con caja rellena de neopreno, pero con movilidad en una sola dirección. El disco de Teflon puede ser circular o rectangular. La caja del neopreno es una placa cuadrada de acero guiada por dos listones del mismo material en la dirección de la movilidad. Para disminuir el rozamiento producido por fuerzas horizontales normales a la dirección móvil se colocan pequeñas tiras de Teflon en las paredes verticales de las guías. La superficie deslizante de la placa de acero se protege también con chapa atornillada.

Los valores mínimos de $\mu$ se obtienen para $p=400$ a $500 \mathrm{kp} / \mathrm{cm}^{2}$, pero, por otra parte, el neopreno no debe cargarse a más de $p=300 \mathrm{kp} / \mathrm{cm}^{2}$, y este valor aún debe ser menor para sobrecargas parciales (por ejemplo: cuando falta la móvil). Esto conduce, como solución conveniente, a poner áreas deslizantes de Teflon que sean menores que las áreas de neopreno. Esto se realiza poniendo pequeños discos o tiras de Teflon a distancias convenientes: el área deslizante es así menor y la presión sobre el Teflon es mayor que la que corresponde a un disco grande (fig. 22, a, b, c). Las presiones que actúan sobre las partes situadas por encima de la placa deslizante o sobre el techo de la caja no se alteran debido al efecto de repartición de la placa de acero, siempre que la distancia entre los pequeños discos o tiras de Teflon sea menor que, por ejemplo, el doble del espesor de la placa. Los discos de Teflon se introducen en rehundidos de $1,5 \mathrm{~mm}$ de profundidad. Pueden también colocarse en una chapa agujereada (fig. 22 , b) y colocada después en el techo de la caja del neopreno.

$\mathrm{Si}$ en vez de pequeños discos se ponen tiras o bandas estrechas de Teflon, los rehundidos en la

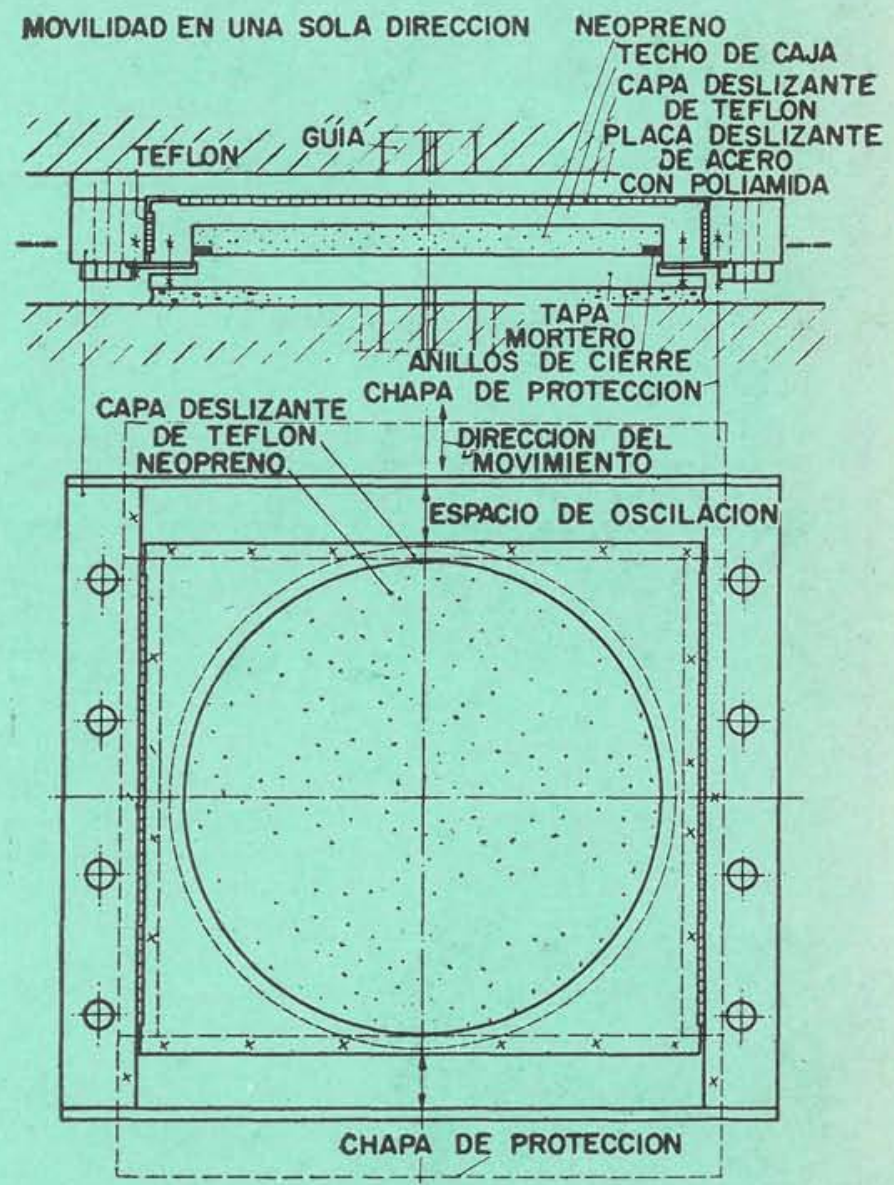

Fig. 21.-Apoyo deslizante con eaja rellena de neopreno.

placa pueden hacerse con la cepilladora y para sujetar dichas tiras se colocan, en sus extremos pequeñas arandelas de acero (fig. $22, \mathrm{c}$ ).

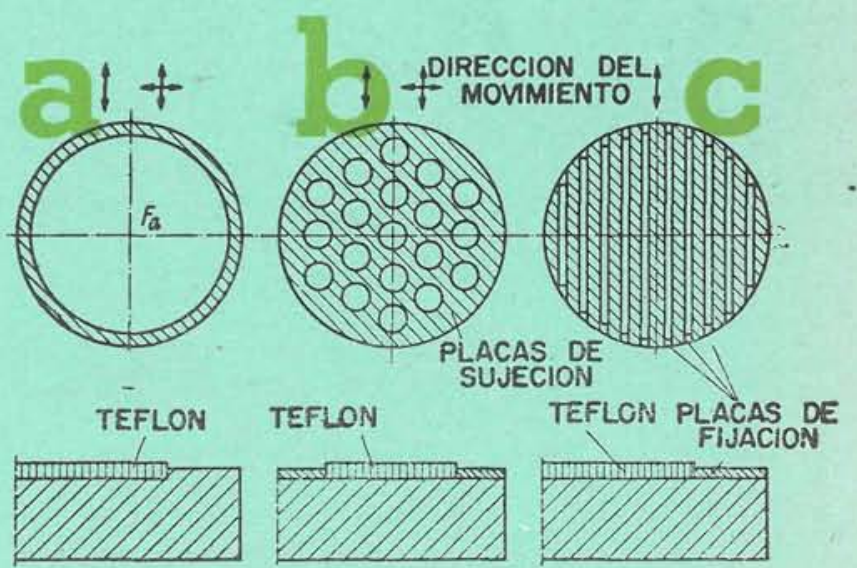

Fig. 22.-Diversós dispositivos de áreas deslizantes de Teflon.

a) Gran placa circular $\mathrm{F}_{a}$.

b) Varias pequeñas placas circulares $\mathrm{F}_{b} \sim 0,4 \mathrm{Fa}$

c) Bandas independientes de placas $F_{c} \sim 0,3 \quad F_{a}$. 


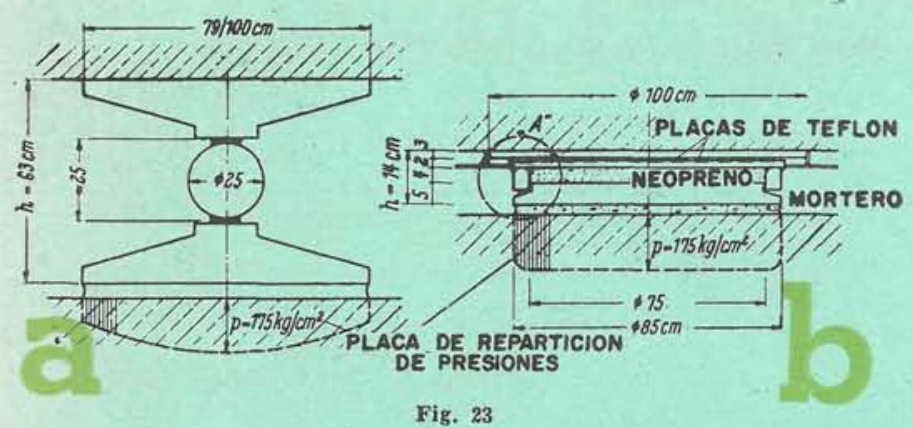

a) Apoyo Corroweld (acero), móvil en una sola dirección. Solicitación total, $1.000 \mathrm{Mp}$; presión del hormigón, $\mathrm{p}=175 \mathrm{kp} / \mathrm{cm}^{2}$; presión de Hertz, $a=17 \mathrm{Mp} / \mathrm{cm}^{2}$; carga de flexión en la placa de arriba, $\sigma=2,1 \mathrm{Mp} / \mathrm{cm}^{2}$; peso del acero, $\mathrm{G}=1.850 ;$ altura, $\mathrm{h}=63 \mathrm{~cm}$.

Apoyo deslizante y caja con neopreno, móvil en todas direcciones, para solicitación de $1.000 \mathrm{Mp}$ (como el anterior). Presión del hormigon, $p=175 \mathrm{Mp} / \mathrm{cm}^{2}$ (como el anterior); presión en la placa de np/ $\mathrm{cm}^{2}$, $\mathbf{p}=225 \mathrm{kp} / \mathrm{cm}^{2}$; presion en la capa de Teflon, $\mathbf{p}=400$ peso del acero, $\mathrm{G}=590 \mathrm{~kg}$; altura, $\mathrm{h}=14 \mathrm{~cm}$.

El apoyo deslizante combinado con la caja rellena de neopreno se coloca como los corrientes. Resulta muy conveniente el peso reducido. Para que la placa deslizante no se corra hacia la caja del neopreno, el borde de la primera se atornilla en varios puntos con el anillo de protección soldado al borde de la caja. Los tornillos son débiles y se parten con la solicitación o bien se retiran después del montaje.

En la figura 23 a, se dan las dimensiones de un apoyo de rodillo móvil en una sola dirección para una presión total de $1.000 \mathrm{Mp}$, y en la figura $23 \mathrm{~b}$, como comparación, las dimensiones de otro apoyo de capas deslizantes y caja llena de neopreno, para la misma solicitación total y, además, móvil en todas las direcciones. La presión sobre el hormigón del plano de asiento es la misma en ambos casos, o sea, máximo $175 \mathrm{kp} / \mathrm{cm}^{2}$; el camino de recorrido

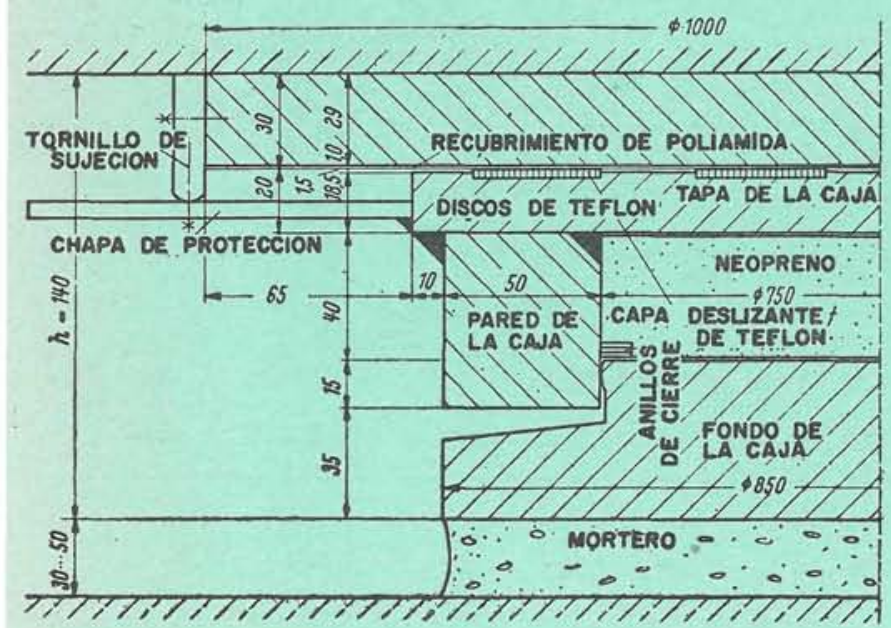

Fig. 24.-Detalle «A» de la figura 23, apoyo deslizante y caja con neo. preno (medidas, en $\mathrm{mm}$ ). es $-7,5 \mathrm{~cm}$ [para a) en una sola dirección; para b) en todas las direcciones].

El apoyo de rodillos [el a) todo de acero] pesa, aproximadamente, $1.850 \mathrm{~kg}$; las placas están sometidas a unas cargas de flexión de $2,0 \mathrm{Mp} / \mathrm{cm}^{2}$; las superficies de rodadura a una presión de Hertz de $17 \mathrm{Mp} / \mathrm{cm}^{2}$. La altura del apoyo es $64 \mathrm{~cm}$. Frente a estos datos, tenemos para el apoyo deslizante y caja con neopreno: peso de $590 \mathrm{~kg}$, o sea, $\sim 1 / 3$ del primero; altura, $14 \mathrm{~cm}$, o sea, $1 / 4$ del primero; no se necesitan grandes nichos ni escotaduras para su instalación.

En estricto rigor, la comparación entre los dos apoyos debería hacerse siendo el primero móvil en todas las direcciones. Resultaría aún más patente la superioridad del apoyo deslizante y con capa de neopreno.

\subsection{Dimensionado de los apoyos de caja rellena de neopreno.}

Como resultado de los ensayos puede admitirse para carga práctica admisible del neopreno a compresión el valor $p=N / F_{\mathrm{G}}=300 \mathrm{kp} / \mathrm{cm}^{2}$. Para espesor de la placa de neopreno basta con $h=d / 15$ cuando arriba y abajo se ponen capas deslizantes de Teflon o Molikote; y de $h=d / 8$ cuando se prescinde de estas capas. La excentricidad de las sobrecargas no se tiene en cuenta mientras no den lugar a ángulos de giro que excedan de 0,02.

Para el fondo y tapa de las cajas basta un espesor de chapa de acero $t=d / 30 \geqq 10 \mathrm{~mm}$, a no ser que, por razones especiales, se necesiten espesores mayores o menores. El esfuerzo de tracción circular, $Z=p d h / 2$, se aplica solamente al anillo soldado a la caja, y se aplican las cargas prácticas admisibles para el acero de calidades 37 ó 50 (en alemán: $\mathrm{St}=\mathrm{Stahl}=$ acero). Las costuras de soldadura del fondo de caja se dimensionan de modo que dicho fondo se adapte a las deformaciones del anillo.

Las capas deslizantes de Teflon en los apoyos deslizantes deben dimensionarse de modo que, a plena sobrecarga, la presión no exceda de 300 a 500 $\mathrm{kp} / \mathrm{cm}^{2}$ para que el coeficiente de rozamiento sea pequeño. La superficie deslizante de las placas de acero debe ser, en lo posible, perfectamente plana y llevar un recubrimiento de poliamida dura o de cromo endurecido.

La fuerza de rozamiento que se opone al deslizamiento actúa sobre la infra y la superestructura; se estima en un 3 por 100 de la sobrecarga de solicitación. Las sobrecargas pequeñas con sus correspondientes índices de rozamiento mayores no producen mayores rozamientos antideslizantes, pues $\mu$ crece, pero menos de prisa que la disminución de $p$. 
Estas reglas de dimensionado suponen un coeficiente de seguridad igual a 3 ; para posibles modificaciones habrá que esperar a los resultados de la experiencia recogida en el transcurso del tiempo.

\section{Posibillidades futruras}

Con los apoyos que hemos descrito no hemos agotado las posibilidades que se prevén para un inmediato futuro.

Los apoyos con caja de neopreno, de planta circular, son verdaderas articulaciones, aptas especialmente, para soportar grandes sobrecargas, con movilidad en todas las direcciones y ocupando un espacio reducido. La forma circular, en este caso, es la más adecuada, por ser la que más se acerca al giro puntual característico de las articulaciones de acero.

Con los apoyos de caja rellena de neopreno puede también conseguirse fácilmente un apoyo lineal, poniendo varios de ellos a lo largo de la línea de apoyo. Sin embargo, en este caso se pierde la movilidad de giro en cualquier dirección y la planta circular no ofrece ninguna ventaja. Por lo tanto, cuando las sobrecargas de la superestructura deban repartirse a lo largo de una línea-como sucede en los puentes de gran anchura-debe prescindirse de la planta circular. Como las fuerzas repartidas a lo largo de una línea son pequeñas, convienen apoyos estrechos y largos. Frente a los apoyos corrientes de acero, los de neopreno van perdiendo ventaja a medida que va siendo menor la sobrecarga sobre cada apoyo.

Por lo tanto, en aquellos casos de apoyo líneal en que no sea necesaria la movilidad en todas las direcciones, conviene adoptar apoyos largos y estrechos para que sea más uniforme el reparto de la sobrecarga.

La solución más ventajosa y económica es utilizar - en estos casos-apoyos de acero, análogos al representado en la figura la, y que al ser largos y estrechos la sobrecarga repartida es pequeña y las placas de distribución y de asiento pueden ser más delgadas.

Estos apoyos lineales de acero pueden combinarse con intercalación de capas deslizantes de Teflon, con lo que es posible obtener, además del giro (articulación), un pequeño recorrido horizontal de deslizamiento. En la figura 25, la pieza intermedia lleva embutida en su cara superior una placa de Teflon sobre la que puede resbalar la placa de arriba, que es de acero y va recubierta en su cara inferior con plástico o cromo endurecido. La disposición indicada impide el ensuciamiento de las superficies

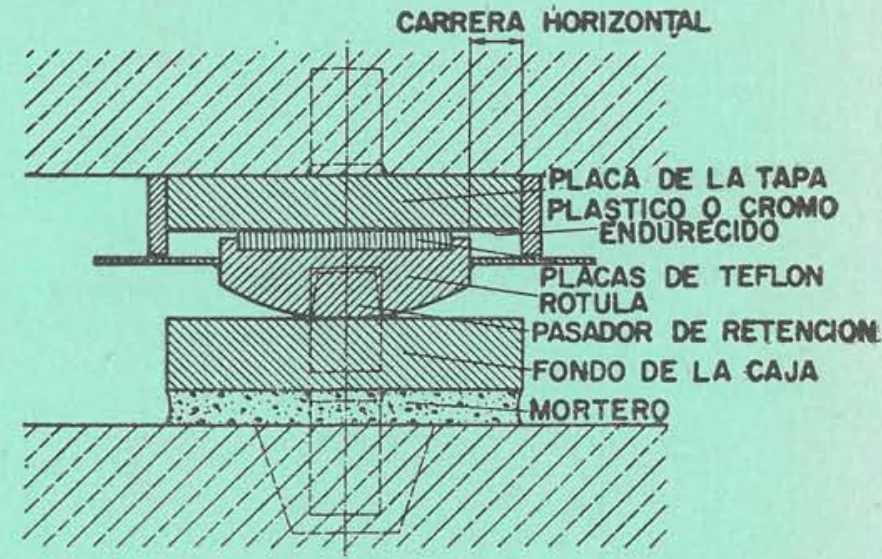

Fig. 25. - Apoyo lineal deslizante $y$ de giro, movilidad en todas las direcciones; para solicitaciones pequeñas.

deslizantes. Las partes externas expuestas a la intemperie llevan un recubrimiento de plástico o metal para preservarlas de la corrosión.

Cuando es grande la sobrecarga por unidad de longitud de apoyo se emplean, arriba y abajo, placas de mayor espesor para centrar bien la sobrecarga
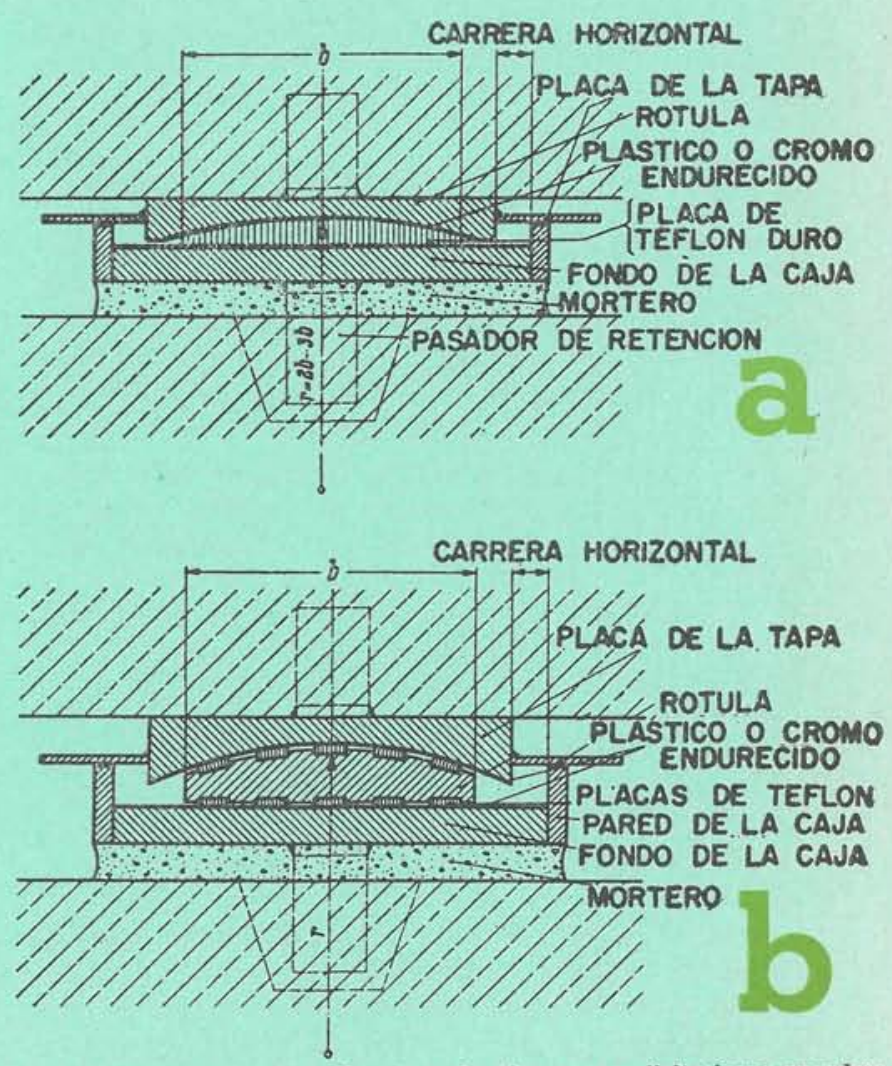

Fig. 26.-Apoyo lineal deslizante $y$ de giro para solicitaciones grandes: a) Placa intermedia de Teflon (con relleno de fibra de vidrio o grafito). b) Placa intermedia de metal con tiras de Teflon embutidas. 


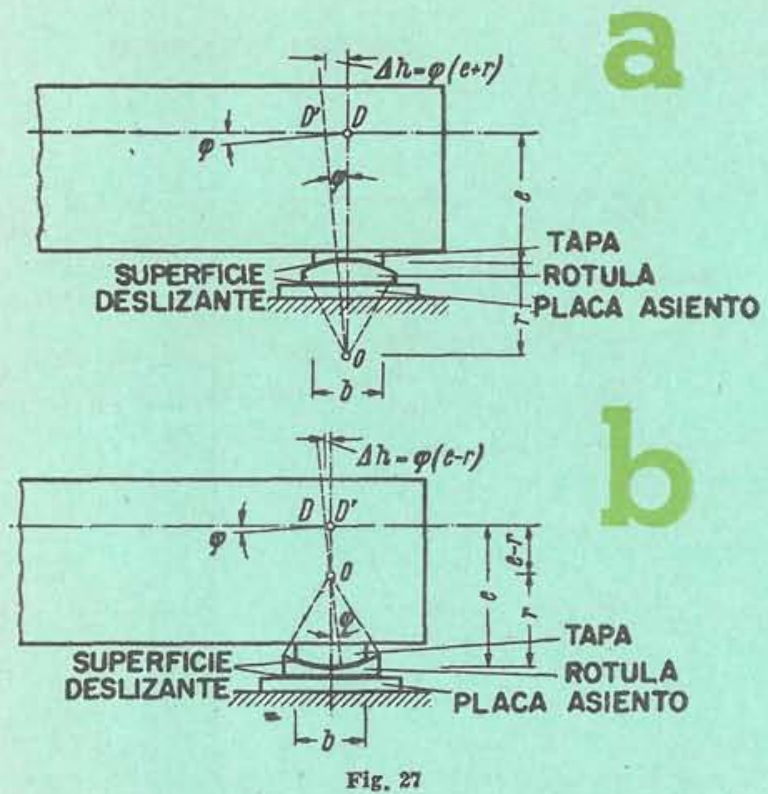

a) Corrimiento horizontal debido al giro, superficies deslizantes cilindricas cóncavas hacia abajo. b) Corrimiento horizontal debido al giro; superficies deslizantes
cilindricas cóncavas hacia arriba.

sobre la pieza intermedia que lleva en sus dos caras láminas o bandas de Teflon, como en las figuras 26 , a y b. Podemos observar que la banda estrecha de la figura 25 se ha sustituido por otras mucho más anchas.

Con ambos dispositivos (los de 26 a y b), la placa de arriba puede girar sobre la pieza intermedia; para ello va recubierta en su cara inferior con plástico o cromo endurecido. Pero, a su vez, la pieza intermedia puede resbalar sobre la placa de asiento y ésta última tiene también su cara superior bruñida y recubierta con plástico o cromo endurecido.

Con ambos dispositivos, el pequeño giro efectuado por la placa de arriba al resbalar sobre la pieza intermedia, combinado con el pequeño deslizamiento de ésta sobre la placa de asiento, producen un giro de la superestructura alrededor del punto $O$, como se ve claramente en la figura 27a. La superestructura gira alrededor del punto $D, y$ al mismo tiempo efectúa el recorrido horizontal $D D^{\prime}$. De la simple inspección de la figura se deduce que el arco $D D^{\prime}=$ áng $\times$ radio $=\varphi(e+r)$, en que: $\varphi=$ ángulo de giro; $e=$ distancia del punto $D$ a la superficie cilíndrica; $r=$ radio de esta superficie.

Cuando el recorrido horizontal debido al giro es demasiado grande comparado con el del deslizamiento, puede disponerse la superficie cilíndrica con la concavidad hacia arriba (fig. $27 \mathrm{~b}$ ) y en este caso, $r$ es negativo. Cuando $r=-e$, el recorrido horizontal debido al giro se hace nulo.
En general, se procura elegir $r$ relativamente grande para que la placa intermedia resulte ancha y aplanada. Ya hemos dicho que las dos caras de esta capa llevan Teflon: en la de la figura $26 \mathrm{~b}$ se han puesto tiras o bandas en lugar de láminas para que sea mayor la presión unitaria y, en consecuencia, menor el coeficiente de rozamiento. Las fuerzas de rozamiento (que se oponen al deslizamiento) que se producen en la superficie cilíndrica como consecuencia del giro producen un momento de flexión que es tanto más pequeño cuanto menor es el rozamiento y el radio $r$. Se comprueba fácilmente que, con un radio $r=2$ a $3 \mathrm{~b}$ y un coeficiente de rozamiento reducido, como, por ejemplo, $\mu=1$ por 100 , el momento de flexión es despreciable.

De las figuras $26 \mathrm{a}$ y b se deduce que el consumo de material en estos apoyos de giro (en una sola dirección) y deslizamiento es muy reducido. Con el mismo principio pueden construirse apoyos de giro puntual, posible en todas las direcciones, sustituyendo las superficies cilíndricas por otras esféricas. La pregunta de hasta qué punto estos apoyos pueden ser más económicos que los de caja con neopreno, sólo podrá responderse en el futuro. Pero es de esperar que con grandes presiones de sobrecarga resultarán más convenientes los de caja con neopreno, ya que la fabricación de las piezas de acero esféricas va siendo cada vez más costosa a medida que van aumentando sus dimensiones.

Un posible dispositivo senuillo es el representado en la figura 28. Aquí se ha suprimido la tapa de la caja del neopreno y hace sus veces la placa de asiento de la superestructura sobre el apoyo. La cara inferior de esta placa está bruñida y lleva un recubrimiento de plástico o cromo endurecido. Puede, por lo tanto, resbalar fácilmente sobre una placa gruesa de Teflon duro (fabricado, por ejemplo, con relleno de fibras de vidrio). Esta placa tiene forma de caja y envuelve una capa de Teflon o de neopreno, que son materiales plásticos que han de permitir los pequeños giros. Finalmente, la placa de Teflon o neopreno va adherida al fondo de la placa de asien-

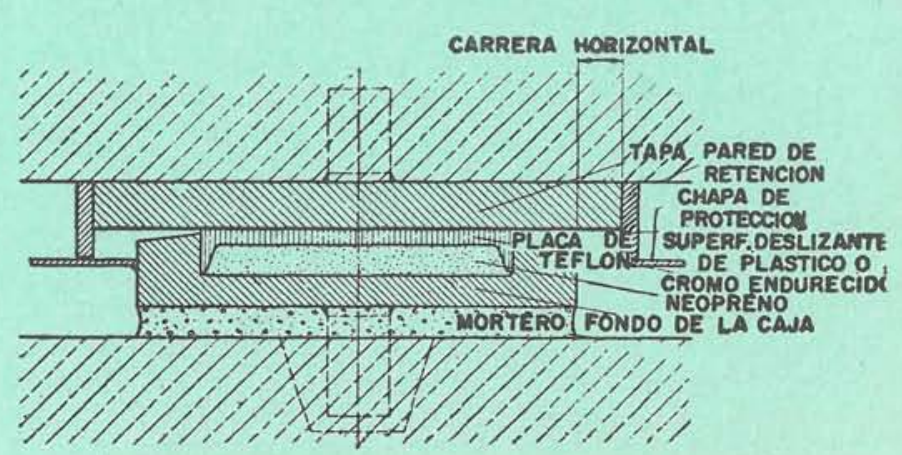

Fig. 28.-Apoyo de giro lineal y deslizamiento para pequeños ángulos de giro. 


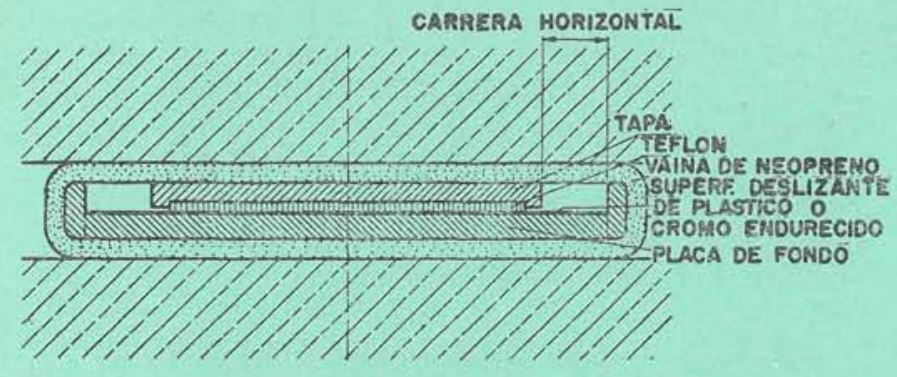

Fig. 29.-Apoyo deslizante de Teflon para grandes corrimientos horizontales, pequeños ángulos de giro $\mathrm{y}$ presiones moderadas.

to sobre el cimiento; esta placa tiene también forma de caja y lleva los biseles que se ven en la figura con el huelgo necesario para permitir los pequeños giros. Una chapa horizontal y dos listones de acero cierran la caja preservándola de la acción de las humedades, polvo, etc.

Para pequeños ángulos de giro, presiones moderadas y grandes recorridos horizontales se ha ideado el apoyo representado en la figura 29. Las dos superficies deslizantes son la de la cara inferior del Teflon y la cara superior del fondo de caja que va bruñida y con un recubrimiento de plástico o de cromo endurecido. La capa de Teflon queda aprisionada entre la tapa y el fondo de la caja. El apoyo queda envuelto por una especie de tubo de sección rectangular de neopreno, Teflon o de materiales análogos que lo protegen contra la corrosión. Tanto la eara superior de la tapa como la inferior de la caja están unidas a la envolvente por rugosidad, pero este enlace no impide los movimientos horizontales del apoyo. Los giros tienen que ser pequeños, pues están limitados por el pequeño huelgo que tiene la tapa, según podemos ver claramente en la figura.

Finalmente, indicaremos un dispositivo especial de apoyo, que se distingue por su sencillez (fig. 30). Las superficies deslizantes son: por un lado, la cara inferior de la placa de asiento de la construcción que, como siempre, está pulida y recubierta con

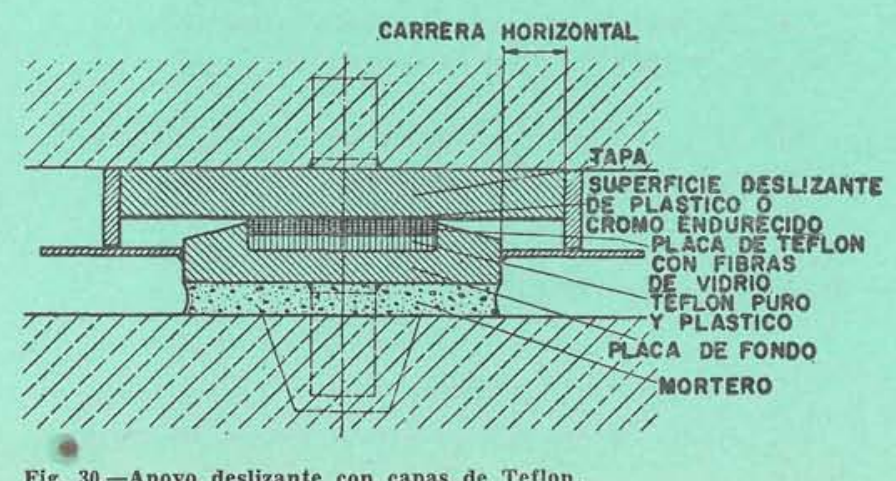

Fig. 30.-Apoyo deslizante con capas de Teflon. plástico o cromo endurecido; y por otro lado, una placa relativamente gruesa de Teflón duro (por ejemplo, tejido reforzado con fibra de vidrio) con escasa o nula plasticidad. Debajo de la capa de Teflon duro va una capa de Teflon puro blando, muy plástico, que es el que permite los pequeños giros del apoyo. Ambas placas de Teflon van embutidas en la caja de asiento sobre la infraestructura, que tiene las paredes verticales terminadas en biseles con suficiente huelgo respecto a la tapa para permitir los giros. En la figura se ven los listones (acero) laterales y la chapa horizontal para protección contra la humedad, el polvo y la corrosión. Claro está que en vez de esta capa de Teflon plástico podría ponerse otra de material plástico, por ejemplo, neopreno, siempre que no pueda escapar por la junta que existe entre la placa de Teflon duro y la pared lateral de la caja de fondo.

En la actualidad se están efectuando ensayos sistemáticos de estos apoyos en el Laboratorio (oficial) de ensayos de Stuttgart y que tienden, principalmente, a fijar las dimensiones más convenientes y materiales más apropiados para distintas presiones, deslizamientos y ángulos de giro.

En resumen, puede afirmarse que, con el empleo del neopreno, el Teflon o materiales de análogas propiedades, existe la posibilidad de fabricar apoyos que cumplen las debidas condiciones estáticas y constructivas, con un mínimo de material y trabajo, o sea, con un máximo de economía.

\section{Obsemvacción}

Los nuevos apoyos aquí descritos representan una simplificación considerable comparada con los de acero, corrientes hasta la fecha. Los apoyos de caja con neopreno permiten realizar del modo más sencillo el centrado de las sobrecargas grandes y muy grandes (véase, por ejenıplo, el de la figura 12, para $5.000 \mathrm{mp}$ ) con una perfección imposible de conseguir hasta ahora, incluso empleando articulaciones de segmento esférico construidas de acero (giro alrededor de un punto, en cualquier dirección). Las capas de neopreno pueden cargarse hasta $400 \mathrm{kp} / \mathrm{cm}^{2}$; como carga práctica admisible corriente, se señala la de $300 \mathrm{kp} / \mathrm{cm}^{2}$; de este modo resul$\tan$ apoyos de pequeñas dimensiones.

Con los nuevos materiales deslizantes: el Teflon, por un lado, y por otro, la placa de acero bruñida y recubierta de poliamida o de cromo endurecido, pueden construirse apoyos que soporten grandes sobrecargas y cuya resistencia al deslizamiento es muy inferior a la señalada en las normas DIN 1072 para los apoyos de rodillos de acero. Para conseguir este efecto, es esencial que la capa de Teflon quede fuertemente comprimida (de 300 a $500 \mathrm{kp} / \mathrm{cm}^{2}$ ), pues 
solamente cuando el material queda sometido a presiones altas es cuando baja sensiblemente su coeficiente de rozamiento.

Los nuevos apoyos con capas deslizantes y caja con neopreno tienen poca altura de construcción; casi la misma que los apoyos completamente fijos (empotramientos) de modo que, por ejemplo, en los puentes, los apoyos con movilidad no tienen mayor altura que los fijos; lo cual tiene su importancia, no sólo desde el punto de vista estático, sino también en el aspecto externo de estas importantes construcciones.

Los apoyos con caja rellena de neopreno, fijos o deslizantes, necesitan para su fabricación poco consumo de acero y de neopreno, porque las sobrecargas grandes no necesitan ser centradas en la placa de apoyo de la superestructura para evitar las flexiones, sino que se reparten por toda el área de la placa de neopreno. Los nuevos apoyos resultan así, no sólo más económicos, sino también más sencillos de fabricación; el acabado sólo requiere especial esmero en algunos detalles.
La idea y desarrollo de estos apoyos ha sido fruto de un trabajo realizado por los autores de este artículo, con la colaboración del Insp. Beyer, de Düsseldorf; Dipl.-Ing. Wintergerst, de Esslingen (Neckar) y de la fábrica de máquinas ME (Maschinenfabrik, Esslingen). Esta fábrica ha adquirido los derechos de patente y se ha encargado de la fabricación y del suministro de los apoyos.

Los ensayos fueron subvencionados por la ciudad de Düsseldorf, la región (país) de Baden-Württemberg y la fábrica de máquinas de Esslingen. Fueron realizados, en parte, en el Instituto Otto-Graf, bajo la dirección del Prof. Dr.-Ing. Weil; los ensayos de deslizamiento se hicieron en el MPA (MaterialPrüfungs-Anstalt = laboratorio de ensayo de materiales) de la $\mathrm{TH}$ (Technische Hochschule = Escuela Politécnica) de Stuttgart, bajo la dirección del Profesor Dr.-Ing. habil. Wellinger. Expresamos aquí nuestro más profundo agradecimiento al Dr.-Ing. Klingenberg, dependiente del Ministerio de Bonn, por su valiosa intervención en favor del empleo de estos nuevos apoyos en los puentes.

(10) Maschinenfabrik Eßlingen, Druckschrift für Corroweld-Lager. Eßlingen 1960.

(11) Versuchsbericht der Staatl. Materialprüfungsanstalt an der TH Stuttgart vom 15. 2. 1961.

(12) Versuchsberichte des Otto-Graf-Institutes an der TH Stuttgart vom 26. 6. 1959, 29. 6. 1959, 9. 12. 1959, 5. 4. 1961.

(13) Untersuchungsbericht über Gummischichtlager der EMPA (*) Zürich Nr. 74662 im Auftrag der Proceq vom 12, 5. 1961 . A-10 542 der Fa. Du Pont de Nemours \& Co., Elastomer Chemicals Department. April 1959.

(5) Ott, K. E.: Synthetischer Kautschuk als Werkstoff. VDI-Zeitschrift 1961, H. 11.

(6) Leonhardt, F. und Andrä, W.: Stützungsprobleme der Hochstraßenbrücken. Beton- und Stahlbetonbau 55 (1960), H. 6.

(7) Beyer und Wintergerst: Neue Brückenlager, neue Pfeilerform. Der Bauingenieur 35 (1960) H. 6.

(8) Allgemeiner Runderla $\beta$ Straßenbau Nr. 9/1959, Sachgebiet 5 Brückenbau, des Bundesministers für Verkehr, St B - 3 Ibn - 2160 Vms 59.

(9) Maschinenfabrik Eßlingen, Versuchsbericht vom 31. 8. 1959 über Brückenlager, Staatl. Material-Prüfungsanstalt an der TH $\left({ }^{*}\right)$ Stuttgart.
(14) Nichtveröffentlichte Versuche der New York-Hamburg. Gummi-Wasren Compagnie vom 28. 4. 1961.

(15) Druckschrift der Fa. Vorspann-Technik G.m.b.H. «Allseitig bewegliche Gummilager». Aug. 1960.

(16) E. I. Du Pont de Nemours and Co., Wilmington, Delaware, USA: New Design Data for Teflon, Januar 1960.

(17) Topaloff: Gummilager für Brücken. Beton- und Stahlbetonbau 54 (1959) H. 9.

(*) $\mathrm{TH}=$ Escuela Politécnica.

(***) EMPA = Laboratorio Federal de Ensayo de Materiales. 


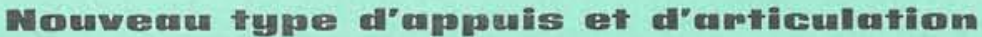

Fritz Leonhardi et Wolfhart Andrä, ingénieurs.

Les tendances actuelles de la construction sont fonctions, directement, de la présence croissante et améliorée des matériaux de construetion offerts sur le marché. Dans le domaine des matériaux il faut noter une sensible subdivision en riaux de construetion offerts sur le marché. Dans le domaine des matériaux il faut noter une sensible subdivision en naturels, préparés ou synthétiques, ces derniers constituant la préoccupation des auteurs de cet article pour leur emploi
et leur bonne application. Parmi les différents membres de cette grande famille, les résines synthétiques ou caoutchouc et leur bonne application. Parmi les différents membres de cette grande famille, les résines synthétiques ou caoutchoue
artificiel jouissent, dans cette étude de nouveaux types d’appuis présentés par les éminents ingénieurs allemands Wolfhart artificiel jouissent, dans cette étude de nouveaux

Aux essais de laboratoire et à l'échelle naturelle, les variétés commerciales de ces résines connues sous la dénomination de «neopreno» et «teflon ont été choisies pour présenter, au moins actuellement, des caractéristiques très appropriées pon le but poursuivi dans cette étude, de laquelle on espère un développement ultérieur et un meilleur accueil pour les importantes applications qui en dérivent dans le domaine du génie civil et de la construetion.

Les auteurs étudient avec attention et une rigueur, peut-être exeessive pour les applications pratiques, les déformations que l'on peut attendre de ces matériaux soumis à des forces de grande concentration.

Pour les appuis, la distribution de la charge, toujours concentrée sur des surfaces relativement petites, joue un rôle particulier, ce qui exige des charges unitaires élevées et, par conséquent, l'utilisation de matériaux extrêmement nobles pour les résister avec la résistance que les déformations instantanées requièrent pour retrouver rapidement la position de stabilité momentanément perdue, La fatigue, dans le cycle de déformations, relâche les matériaux et l’on doit en tenir compte à considérer les caractéristiques que doivent avoir les matériaux employés pour les appuis.

Si l'on mène les choses à des limites extrêmes, on constate avec plus de facilité l'importance d'un phénomène et, si nous considérons un appui imaginaire de surface de sustentation réduite, nous comprendrons qu'à la limite, les efforts peuven présenter (eas extrêmement rare) des caractères punetiformes ou linéaires on, plus graphiquement, d'aiguille ou de fil incisif, de conséquences graves.

La présence de ces matériaux et leur application rationnelle réduisent considérablement les surfaces de sustentation nécessaires, jusqu'à ce jour, avec les matériaux ordinaires.

Un autre phénomène à considérer est la rigidité nécessaire, en beaucoup de cas, que les auteurs ont également étudiée analytiquement dans ce travail.

Les comparaisons entre les appuis et les articulations ordinaires et ceux qui sont obtenus à l'aide des nouveaux matériaux sont traités avec un rare bonheur.

Les auteurs ont réservé un ample espace aux différentes sortes d’appuis, qui accompagne une information graphique précieuse et clairement distribuée pour les possibles applications.

Une caraetéristique importante est la mobilité qui, en certains cas, doit être exigée des appuis, ceux-ci devant permettre certains mouvements dus à différentes causes comme, par exemple, les différences de température. Cette particularité a été considérée et a fait l'objet d'une étude dans ce travail.

L'appui a ses dimensions optima dont la détermination a été traitée avec suffisamment de détails pour les applications ordinaires exigées par la pratique.

Les auteurs ont également laissé prévoir les possibilités futures qui s'offrent à ce nouveau type d'appui.

Pour terminer, ce travail s'achève par une série d'objections de caractère technico-théorique de tous les types d'appui qui ont été traités dans le texte et les auteurs expriment leur connaissance aux différentes personnalités et organismes alle. mands qui ont prêté leur collaboration pour la réalisation de ce travail.

\section{New thype of supporths cumed lhängess}

Fritz Leonhardt and Wolfhart Andrä, engineers.

Modern constructional tendencies are largely dependent on the increasing variety and improvement of building materials available in commercial quantities. These materials can be divided into natural and synthetic, and the distinguished engineers Leonhardt and Andra discuss the best uses of synthetic resins and artificial rubber, as applied to new types of supports and hinges.

In laboratory and full seale tests, the commercial versions of resins known as Neoprene and Teflon have been chosen as being, at least for the time being, specially suitable for the purposes envisaged by the above authors. They hope that these materials will find a growing number of uses in the field of engineering and construction.

The authors have carried strict and detailed investigations on the strength and elastic properties of these resins, when subjected to high stresses. 
High quality materials are required to withstand the concentrated stresses close to the points of application of the loads. The fatigue effect, as a long time weakening process, must also be carefully considered.

These concentrated loads, in limiting cases, may be likened in their effect to that of sharp points or edges. The new materials make it possible to reduce considerably the loadings areas.

A further factor to be taken into account is the structural rigidity, which the authors have studied closely, relating it to the flexibility at the points of support and at the hinges. The various types of supports have been diseussed, and graphical information on their possible uses has been provided.

Specific functional requirements demand corresponding measures of flexibility at the supports, as, for instance, allowance for dilations, due to temperature changes. Furthermore, the points of support of a structure should have an optimum cross sectional area, depending on the other circumstances.

Finally the authors refer to the future possibilities of these new types of supports, and they indicate a number of theoretical and technical difficulties inherent in these bearings: they also express acknowledgement to German individuals and institutions, for their contribution to this investigation.

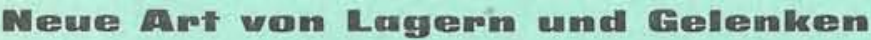

Fritz Leonhardt und Wolfhart Andrä, Ingenieure.

Die gegenwärtigen Neigungen sind Funktionen, welche direkt von der steigenden und verbesserten Gegenwart der Baustoffe, die im Handel geboten werden, abhängen. Auf dem Gebiete der Materialien ist eine deutliche Unterteilung in natürliche und vorgefertigte oder künstliche getroffen. Diese letzteren bilden die Besorgnis der Hersteller für ihre Ausnützung und entsprechende Anwendung. Unter ihnen haben sich die Kunstharze oder der künstliche Kautschuk innerhalb der verschiedenen Arten dieser grossen Familie in erster Linie bei diesem Studium der neuen Arten von Lagern erfreut, welehe die ausgezeichneten deutschen Ingenieure Wolfhart Andra und Fritz Leonhardt vorlegen.

In den Laboratoriumsversuchen und denen im natürlichen Masstabe sind unter den Handelsmannigfaltigkeiten diese mit Namen «Neopreno» und «Teflon» bekannten Harze auserwählt worden, um vorgestellt zu werden, die zumindest gegenwärtig für den in diesem Studium verfolgten Zweck besondere Eigenschaften deutlich machen. Das Studium über die letzte Entwicklung erwartet eine gute Aufnahme durch die bedeutsamen Anwendungen, die von ihm auf dem Gebiete des Ingenieur -und Bauwesens abgeleitet werden.

Die Verfasser studieren eingehends und mit äusserster Strenge die Verformungen für die praktischen Anwendungen, welehe von diesen Materialien erwartet werden, wenn man sie stark konzentrierten Kräften unterwirft.

Bei den Lagern spielt die stets konzentrierte Lastenverteilung auf verhältnismässig kleinen Oberflächen eine besondere Rolle, was erhöhte einheitliche Lasten erfordert und damit die Verwendung von äusserst edlen Materialien, um ihnen mit dem Widerstand $\mathrm{zu}$ begegnen, welche die augenblicklichen Verformungen erfordern, um schnell die vorübergehend verloren Festigkeitslage zurückzuerhalten. Die Ermüdung im Kreislauf der Verformungen schwächt die Materialien, und dies hat man beim Betrachten der Eigenschaften, welche die angewandten Stoffe für die Lager aufzuweisen haben, gegenwärtig zu halten.

Indem man die Dinge bis zu den äussersten Grenzen führt, schätzt man mit grösserer Leichtigkeit die Bedeutung einer Erscheinung, und betrachten wir ein Lager von eingeschränkter Unterstützungsfläche in der Vorstellung, so werden wir verstehen, dass an der Grenze die Kräfte einzelne oder lineare Eigenschaften zeigen können oder, bildlicher ausgedrückt, die eines Nadelstiches oder eines eingeschnittenen Fadens mit schweren Folgeerscheinungen.

Die Gegenwart dieser Stoffe und ihre vernünftige Anwendung reduzieren erheblich die bisher notwendigen Unterstützungs flächen bei den gewöhnlichen Materialien.

Eine andere Betrachtungserscheinung ist die in vielen Fällen notwendige Steifigkeit, welehe die Verfasser ebenfalls in dieser Arbeit analytisch studiert haben.

Mit einzigartigem Erfolge wurden die Vergleiche zwischen den Lagern und Gelenken gewöhnlicher Art und denen, die man mit den neuen Stoffen erhält, behandelt.

Die Verfasser haben den versehiedenen Arten von Lagern viel Raum gelassen, die von wertvollem Bildmaterial begleitet werden, welches für die möglichen Anwendungen mit Randbemerkungen gebührend versehen wurde.

Eine wichtige Rolle spielt die Beweglichkeit, die in bestimmten Fällen von den Lagern verlangt wird, da diese gewisse Bewegungen durch verschiedene Ursachen zuzulassen haben, wie beispielsweise Temperaturunterschiede. Diese Besonderheit war Anlass des Studiums und der Betrachtung in dieser Arbeit.

Das Lager hat seine besten Ausmasse, deren Bestimmung mit genügender Genauigkeit für die gewöhnlichen Anwendungen, die die Praxis fordert, behandelt wurde.

Ebenfalls haben die Verfasser die künftigen Möglichkeiten angedeutet, die sich dieser neuen Art von Lagern bieten.

Endlich schliesst die Arbeit mit einer Reihe von Einwänden technisch-theoretischer Art über alle Lager-Typen, die im Text behandelt wurden; sie sprechen den verschiedenen Persönlichkeiten und deutschen Instituten für die von ihnen empfangene Mitarbeit ihren Dank aus. 